Florida International University FIU Digital Commons

FIU Electronic Theses and Dissertations

University Graduate School

3-28-2003

\title{
Identity and intimacy as predictors of adolescent adjustment
}

Melissa L. Adams

Florida International University

DOI: $10.25148 /$ etd.FI13101527

Follow this and additional works at: https://digitalcommons.fiu.edu/etd

Part of the Psychology Commons

\section{Recommended Citation}

Adams, Melissa L., "Identity and intimacy as predictors of adolescent adjustment" (2003). FIU Electronic Theses and Dissertations. 1135.

https://digitalcommons.fiu.edu/etd/1135

This work is brought to you for free and open access by the University Graduate School at FIU Digital Commons. It has been accepted for inclusion in FIU Electronic Theses and Dissertations by an authorized administrator of FIU Digital Commons. For more information, please contact dcc@fiu.edu. 


\section{FLORIDA INTERNATIONAL UNIVERSITY}

Miami, Florida

A thesis submitted in partial fulfillment of the

requirements for the degree of

MASTER OF SCIENCE

in

PSYCHOLOGY

by

Melissa L. Adams 
To: Dean Arthur W. Herriott

College of Arts and Sciences

This thesis, written by Melissa L. Adams, and entitled Identity and Intimacy as Predictors of Adolescent Adjustment, having been approved in respect to style and intellectual content, is referred to you for judgment.

We have read this thesis and recommend that it be approved.

Marilyn J. Mơntgopuery

William M. Kurtines

Jonathan G. Tubman, Major Professor

Date of Defense: March 28, 2003

The thesis of Melissa L. Adams is approved.

Dean Arthur W. Herriott College of Arts and Sciencets

Dean Douglas Wartzok University Graduate School

Florida International University, 2003 


\section{DEDICATION}

I dedicate this thesis to my husband, who has unwaveringly supported my education from the start, and to my mother, whose love and support has always been unconditional. 


\section{ACKNOWLEDGMENTS}

I would like to thank my committee members for their patience and support in the long process of getting this thesis finished. Dr. William Kurtines provided me with the theoretical foundation and the opportunity to develop this project and for that I am grateful. Dr. Marilyn Montgomery's interest in adolescent intimacy and interventions provided much needed assistance. Finally, I would like to express my profound gratitude to my major professor, Dr. Jonathan Tubman, because without his confidence in my ability to finish this project, I would not have been able to.

I would also like to thank my friends and colleagues who were part of this wonderfully rewarding program and whose assistance was invaluable, Laura FerrerWreder, Carolyn Cass Lorente, and Seth Schwartz, as well as the undergraduates whose work was an integral part of this project. Finally, I would like to thank ACE Academy for allowing us the opportunity to be a part of their program, including the students who allowed us to be a part of their lives. 
ABSTRACT OF THE THESIS

\title{
IDENTITY AND INTIMACY AS PREDICTORS OF ADOLESCENT ADJUSTMENT
}

\section{by}

\author{
Melissa L. Adams
}

Florida International University, 2003

Miami, Florida

\section{Professor Jonathan G. Tubman, Major Professor}

Stressful developmental transitions related to identity and intimacy may have significant implications for adjustment in adolescence that last into young adulthood. Social and economic barriers experienced by minority adolescents have attracted attention as significant influences on normative developmental processes and psychosocial adjustment. The primary aim of this study was to describe significant relations among identity, intimacy, and adjustment in a sample of adolescents in an alternative school who were at elevated risk for problem behaviors. A sample of 120 multi-ethnic high school students responded to five self-administered questionnaires. In addition to describing significant gender differences in identity, and internalizing problems, this study documented that measures of identity accounted for significant variance in standard measures of internalizing problems using hierarchical multiple regression. The implications of these results for future research and practice are discussed. 


\section{TABLE OF CONTENTS}

CHAPTER

I. INTRODUCTION AND LITERATURE REVIEW 1

Identity vs. role confusion............................................................... 3

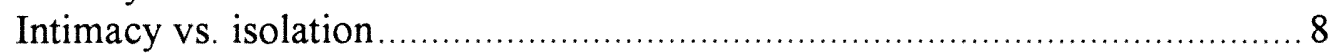

Identity and Intimacy: Timing and Gender ............................................ 14

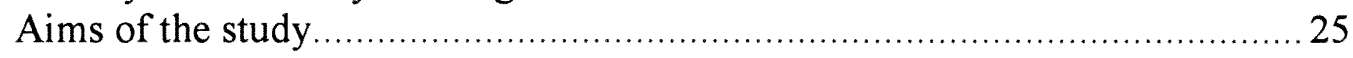

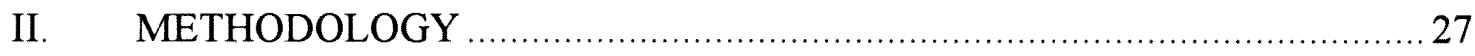

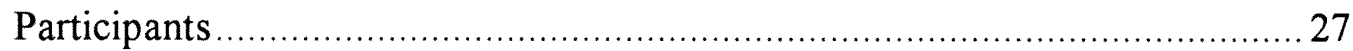

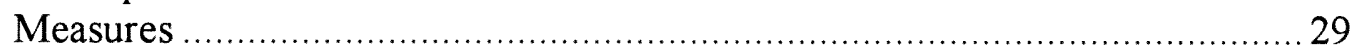

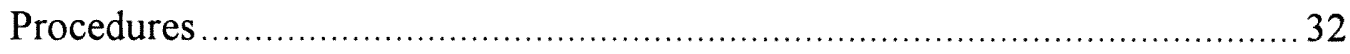

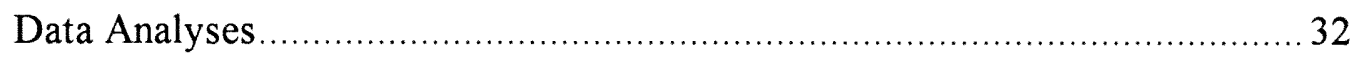

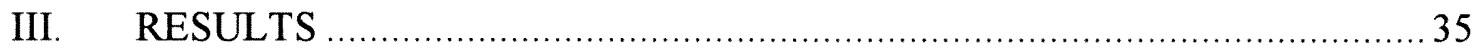

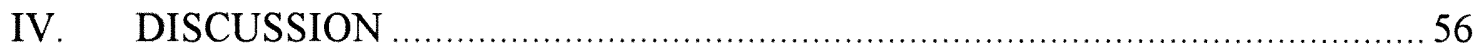

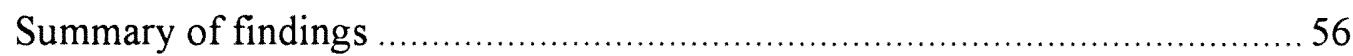

Limitations and Directions for Future Research ......................................... 61

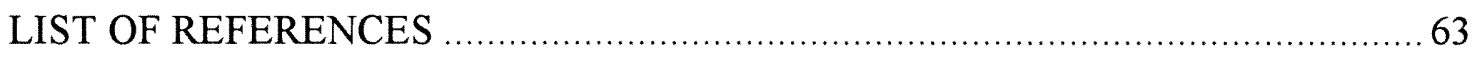

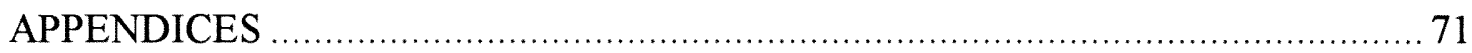




\section{CHAPTER 1: INTRODUCTION AND LITERATURE REVIEW}

In his theory of psychosocial development, Erikson (1968) described eight stages, in which each stage, or crisis, confronts the individual with a "necessary turning point, a crucial moment, when development must move one way or another, marshaling resources of growth, recovery, and further differentiation" (p. 16). At these points, the individual develops alternative basic attitudes, or senses. These "senses" pervade surface and depth, what is conscious and unconscious, by including the dimensions of conscious experiences, which are available for introspection; ways of behaving, which are observable by others; and unconscious inner states, which can be understood only through testing and psychoanalytic interpretation (Erikson, 1968, p. 97).

According to Erikson $(1968,1982)$, the tasks that will eventually lead to a resolution of that particular crisis are resolved in either a positive or negative way. In this manner, the individual either strives to attain and maintain an outcome or strives to avoid or improve an outcome. Although each crisis leaves the individual with both positive and negative attitudes, a successful resolution, one leading to healthy psychological development, is characterized by more positive attitudes than negative. Successful resolutions are considered a foundation for subsequent tasks and each contributes to the accumulation of ego strengths (i.e., a sense of trust versus mistrust, a sense of autonomy versus doubt, a sense of initiative versus guilt, etc.) (Erikson, 1968; Kurtines, 1998).

Erikson (1968) states that in weathering the inner and outer conflicts that emerge and re-emerge, the individual experiences "an increased sense of inner unity, with an increase in good judgment, and an increase in the capacity 'to do well' according to his 
own standards and to the standards of those who are significant to him" (p. 92). At this point, Erikson also uses Maria Jahoda's definition of a healthy personality wherein the individual is able to actively master their environment, to show a certain unity of personality, and to perceive both the world and self correctly. Erikson stated that his intention was "to describe those elements of a really healthy personality which - so it seems to me - are most noticeably absent or defective in neurotic patients and which are most obviously present in the kind of man that educational and cultural systems seem to be striving, each in its own way, to create, to support, and to maintain" $(1980$, p.52).

This formulation suggests that both the individual and the larger society play key roles in a process of negotiation that results in the more or less adaptive resolution of each of these developmental crises. Different individuals may resolve the same dilemma differently, given different circumstances and opportunities, but in the end, the way one decides to resolve these crises has a considerable impact on the quality of a person's life, personally and interpersonally. This point is made by Erikson (1968) when he describes the term crisis as "a crucial period of increased vulnerability and heightened potential, and therefore, the ontogenetic source of generational strength and maladjustment" (p.96).

As some contemporary youth have become increasingly marginalized and vulnerable to negative developmental outcomes, there has been growing recognition of the need to develop interventions to address the needs of this population (Ferrer-Wreder, Lorente, Kurtines, Briones, Bussell, Berman, \& Arrufat, 1998; Milnitsky, Ferrer-Wreder, Lorente, Briones, \& Kurtines, 1998; Rutter, 1990; Winstanley, Meyers, \& Florsheim, 2000). Recently, intervention programs have been developed that target specific groups of high school students identified as being at-risk for behavior problems through processes 
that engage these students and encourage them to reinvest as participants in their own social systems (Ferrer-Wreder, 1998; Ferrer-Wreder, Lorente, Kurtines, Briones, Bussell, Berman, \& Arrufat, 1998; Lorente, C. C., 1998; Milnitsky, Ferrer-Wreder, Lorente, Briones, \& Kurtines, 1998). Unfortunately, the majority of marginalized youth come from inner city, low-income families existing within a community context of disempowerment, limited access to resources, and pervasive violence, crime, and substance abuse. With these risks, there is a clear need to target this population of adolescents to encourage positive development through research and development of effective and efficient prevention programs.

Identity vs. role confusion

Conceptualization of identity. Adolescence confronts the individual with Erikson's fifth and best-known stage of psychosocial development, the task of developing a sense of identity. This is a time when the adolescent is challenged and has the responsibility to make sense of life by choosing goals, roles, and beliefs about the world that give his or her life purpose, coherence, and continuity. This means choosing who one is and what one wants to do with one's life, i.e., choosing a future. Identity development serves to consolidate the development of a sense of self. A successful resolution of this key developmental task is characterized by the integration of past selves from one's childhood (i.e., the selves one has grown up with) and the newly discovered future self, i.e., the self of one's possibilities and potentials, the self one will spend the rest of one's life as (Kurtines, 1998).

Marcia (1966) operationalized identity development as a process of exploration and commitment. While exploration refers to the time that the individual enters a period of struggle or questioning that will result in decisions about his or her identity, commitment 
refers to the moment that the individual makes a firm decision and acts on that decision. These dual processes lead to four possible identity styles or statuses, each of which are based on different underlying intrapsychic structural organizations - referred to as EgoIdentity Statuses (Marcia, 1993). For example, individuals experiencing identity diffusion do not have firm commitments and are not trying to form them, either having explored potential choices without the ability to commit or having never explored. Foreclosure refers to those individual who have not explored options, but who are committed to a particular option, generally reflecting the wishes of their parents or other authority figures. Moratorium refers to individuals who are currently exploring options, trying to find one to which they can commit. Finally, identity achieved describes individuals who have explored appealing options and committed to a particular choice.

The process of identity development has an additional component for adolescents of ethnic minority backgrounds, that is, establishing and integrating an ethnic identity with other aspects of selfhood (Phinney, 1990). This involves in part personally identifying with the values and traditions of one's ethnic group, i.e., establishing a sense of group membership. For some, the first phase is identification with the ethnic majority with a period of exploration following this initial identification, similar to forming a vocational or religious identity (Markstrom-Adams, 1990; Phinney, 1993). Markstrom-Adams and Adams (1995) found that many early adolescents are classified as having a foreclosed or diffused status, having gone along with what they were taught or having never given their ethnic identity much thought. This is in contrast to many middle and late adolescents who appear to move into the moratorium and achieved statuses. Finally, the process of establishing an ethnic identity appears to vary by individual-level factors and processes, beyond simple categorical ethnic differences, where that individual confronts and resolves 
and then may reexamine key issues at later points in time. This leads to the conclusion that the additional process of ethnic identity development makes the already difficult process of identity development more complex and challenging for minority adolescents, who may be disadvantaged and marginalized with respect to social support and other facilitative factors.

Identity and adjustment. According to Erikson (1968), unsuccessful resolution of the identity crisis results in role confusion, where the adolescent is not able to feel meaning and coherence in their life. This confusion places that individual in the position of experiencing difficulty making important decisions critical to their preparation for adulthood and for the formation of adult social relationships, and in particular intimate relationships, which will be discussed later. Research has shown that self-esteem and debilitating emotional states (e.g., anxiety, depression) are related to progress in identity development. Most available studies use Marcia's identity status paradigm for classification purposes.

Higher levels of self-esteem have been reported among individuals with a strong sense of identity (Adams et. al., 1979; Marcia \& Friedman, 1970; Prager, 1982; Schenkel \& Marcia, 1972). Identity commitment appears to be the important dimension here, with individuals assigned identity achieved and, in some cases, identity foreclosed statuses showing higher self-esteem. This finding is, however, more consistent for females than for males (Waterman, 1992). In a study specifically targeting African-American adolescents, Brookins (1996) found that, although African-Americans scored significantly lower on each of the psychosocial task resolution subscales, successful resolution of psychosocial tasks was positively correlated with scores on overall self-concept and emotional wellbeing. 
The process of forming an ethnic identity confronts minority adolescents with several issues that can influence levels of psychological adjustment. This developmental period is one when adolescents must confront the realization that prejudice, discrimination, and negative stereotypes may serve as barriers to their educational and career goals and opportunities. This realization may make them less optimistic, potentially hindering ongoing development (Phinney, 1996; Spencer \& Markstrom-Adams, 1990). In addition, adolescents are becoming aware that members of their own ethnic group, and in particular their peers, are taking an interest in how they are negotiating these issues. Phinney (1996) concludes that "research suggests that the stronger one's ethnic identity, the greater the contribution that that identity makes to one's self-concept" (p.922). Certainly, it seems plausible that if adolescents are having difficulty creating meaning and coherence in their lives, then they will not feel good about themselves or their lives.

Identity development has implications for overall mental health among adolescents as well. Lower levels of debilitating emotional states (including anxiety and depression) have been reported by individuals with a coherent and cohesive sense of identity (Constantinople, 1970; Howard \& Kubris, 1964; Marcia, 1967; Marcia \& Friedman, 1970; Schenkel \& Marcia, 1972; Stark \& Traxler, 1974; Wessman \& Ricks, 1966). However, there have been some studies that have reported no significant findings (Cross \& Allen, 1970; Orlofsky, 1978). Specifically, individuals classified as being in the moratorium identity status consistently report the highest levels of anxiety, while adolescents assigned the commitment status generally report lower levels of anxiety (Waterman, 1992).

In addition to the internalizing problems discussed above, identity development has implications for self-reported levels of externalizing problems. Since exploration is a key process associated with identity development, one must consider that some display of 
externalizing symptoms are developmentally appropriate, and may be integral to the facilitation of identity development. If an adolescent is to make life decisions by active processes of exploration culminating in attaining an achieved identity status, then some level of acting out behaviors would contribute to identity formation and provide protection from becoming withdrawn, depressed, or even anxious about key life decisions. In this way, delinquent or risk-taking behaviors may help to test the limits of autonomy, promoting a cohesive attitude toward the self and a sense of how one can influence the surrounding world.

An important illustration is Moffit et al.'s (1996) work on the development and expression of conduct problems in adolescent males. Their conceptualization states that it has generally been accepted that two primary developmental pathways lead an individual to engage in elevated levels of antisocial behavior. These two pathways share age of onset as the defining feature, with the childhood onset path labeled Life-Course Persistent (LCP) and a later, post-pubertal onset path labeled Adolescence Limited (AL). This model, rather than interpreting acting out behavior as maladaptive, $\mathrm{AL}$ antisocial behavior is seen as a by-product of autonomy assertion that decreases as age brings access to adult privileges and status. This model depicts adolescents as aware of the desirability of adult privileges, specifically those in which they are forbidden to participate. Their behavior is seen as an adaptive response to their rapidly changing social context, implying that nearly all adolescents will engage in some forms of antisocial behavior, with expectable age-related decreases mean levels. Moreover, complete abstinence in risk or delinquent behavior is seen as neither normative nor desirable, considering the implication that these individuals are more likely to be anxious, inhibited, tense, shy, and lacking in social poise (Moffitt, Caspi, Dickson, Silva, \& Stanton, 1996; Krueger, Schmutte, Caspi, \& Moffitt, 1994). 
While this model was formulated to account for age changes in the delinquent behavior of males, it can be proposed that the same general model could be applied to females, with some variations in the content of acting out behaviors.

\section{Intimacy vs. isolation}

Conceptualization of intimacy. Early adulthood is characterized by Erikson as the critical period for addressing and resolving the sixth stage of psychosocial development, the issue of intimacy versus isolation. Intimate relationships are characterized as having the qualities of openness, sharing, trust, self-abandonment, and commitment. In this stage, the person faces the choice between becoming part of an intimate relationship without sacrificing their own identity or alternatively, suffering from isolation due to lack of these types of relationships (Erikson, 1963, 1968, 1980). This developmental task involves willingly making commitments to others and maintaining the ethical strength to abide by those social commitments, even when confronted with tempting alternatives (Adams \& Archer, 1994). In addition, being part of an intimate relationship involves having some insight into, and understanding one's own interpersonal affective needs (e.g., for trust, empathy, care, etc.) as well as insight, understanding, and sensitivity to the interpersonal affective needs of others (Lorente, 1998). The development of intimacy in adolescence is important to study and understand because it highlights key psychosocial accomplishments, provides links to earlier development, and foreshadows adult relationships.

In addition to the theoretical interpretations of Erikson, Orlofsky et al. (1973) developed a status interpretation intended to classify an individual along one of five forms (stages) of the intimacy versus isolation resolution: intimate, pre-intimate, pseudointimate, stereotyped, and isolate. These statuses were conceptualized by Orlofsky (1993), 
not as linear measure of intimacy, but rather as different styles of coping with the demands of close interpersonal relationships. Each status is distinguished by elements of both intimacy and isolation, except for the intimate and the isolate, which contain only that particular style of relating to others.

Briefly, the individual displaying an intimate status is characterized as having deep relationships with male and female friends, as well as an enduring commitment to a significant other. The pre-intimate status is defined by the same deep relationships with friends, however people assigned to this status have not yet entered into an enduring, committed relationship with a significant other and may be ambivalent about such commitments. The people assigned the pseudo-intimate status have entered into a relationship with a significant other. However, the relationship is not characterized by closeness and depth rather it is limited and superficial. The individual assigned to the stereotyped status has some friendships and dating relationships, but they tend to be superficial and conventional with a low degree of communication and closeness. Last, the isolate status is characterized by withdrawal from social situations and lack of personal relationships, except for acquaintances. While Orlofsky's interpretation is conceptually useful, the classification of individuals into discrete categories according to the original interview requires a lengthy interview which makes its use in research difficult and timeconsuming (Orlofsky, 1993).

A broad interpretation proposed by Reis and Shaver (1988) allows for theoretical integration by describing a process-oriented view of intimacy that begins with one person expressing, verbally or non-verbally, personally revealing feelings or information to another person. This continues when the listener responds in a supportive or empathic manner. The interaction becomes intimate when the discloser feels understood, validated, 
and cared for by the listener. Each person's behavior is influenced by the other's behavior and responses, as well as their own pre-existing or situationally-determined motives, needs, and goals. Therefore, although this model suggests that intimacy is in the eye of the beholder, it ultimately requires social interaction and mutual influence as the focus of perception (Reis, 1990). Again, while this view is very broad, it is theoretically useful, serving an integrative function by including common concepts seen as essential to seemingly disparate theories of intimacy: openness-closeness-caring, sharingcommunication-expression, trust-commitment-support, self-abandonment-depth, insightempathy, and understanding-validation.

There is an abundant literature with different and sometimes conflicting definitions and conceptualizations of intimacy that do not add clarity to this discussion. The present study will define and study intimacy as the concept has been presented here. The review of relevant research that follows describes and summarizes the literature that comes closest to our definition of intimacy and is most compatible with our methods and measures.

Intimacy and adjustment. As with identity issues, it appears that intimacy issues do influence, and are influenced by, psychosocial adjustment. As previously discussed, Erikson (1968) described each key psychosocial crisis or challenge as crucial, and therefore the source strength and maladjustment. Unsuccessful resolution of a developmental challenge such as the development of intimacy prescribes that the individual who is not able to become part of an intimate relationship suffers from isolation. The conclusion that adjustment difficulty arises from lack of intimacy can be drawn from other conceptualizations of intimacy as well. For example, viewed from Sullivan's (1953) interpretation, if one is not able to experience intimate interactions, then he or she will not 
experience the validation that leads to a sense of personal satisfaction and security. There are clear associations between intimacy and adjustment in the available research literature.

Research has shown an association between psychological health and intimacy, including feelings of loneliness (Boldero \& Moore, 1990; Craig-Bay \& Adams, 1986; McAdams \& Vaillant, 1982; Rotenberg \& Whitney, 1992; Wheeler, Reis, \& Nezlek, 1983). In addition, a related study also found a relationship between intimacy and physical health. Specifically, the absence of interaction intimacy predicted a greater number of medical care visits (Reis, Wheeler, Kernis, Speigel, \& Nezlek, 1985). Adolescent research on relationships, including friendships, has also found significant associations between adjustment and intimacy. The higher levels of social support and lower levels of peer pressure resulting from intimate relationships (including peer networks/ friendships) were associated with better overall adolescent adjustment, and they were better predictors of adolescent psychological adjustment than measures of popularity (Gavazzi, Anderson, \& Sabatelli, 1993; Townsend, McCraken, \& Wilson, 1988). Research into the relations between the nature of friendships, including attachment, intimacy, and conflict, and several aspects of adjustment, including impulse control, emotional tone, mastery of the external world, and psychopathology has found that the two friendship variables that accounted for significant variance in psychopathology scale scores were attachment and conflict (Claes, 1992). These findings led Claes to conclude that "quality of friendship relations during adolescence participates in the development of psychological adjustment" (p. 53, Claes, 1992).

Minority status among other psychosocial factors may also affect development, Winstanley, Meyers, and Florsheim (2000) conducted a study examining the psychosocial correlates of intimacy achievement in which the participants were mostly minority, 
adolescent fathers-to-be. They found that interpersonal empathy and African American status were significantly associated with intimacy achievement. Highlighting the need for research into the development of intimate relationships with minority and at-risk populations, these researchers called for parents, educators, clinicians, and researchers to recognize how contextual stressors impact the development of adolescent relationships in order to successfully intervene.

Although the statistical associations aren't as unambiguous, and research on developmental changes is limited, similar links between intimacy and adjustment has been found among adults. In a study involving applicants for short-term psychotherapy, having troubled relationships was the most frequent problem cited by $31 \%$ of respondents, withdraws/avoids relationships was $7^{\text {th }}$ cited by $17 \%$, and can't establish relationships was $12^{\text {th }}$ cited by $10 \%$ (Pinsker, Nepps, Redfield, \& Winston, 1985). In an interview study performed by Veroff, Douvan, \& Kulka (1981), when participants were asked to "describe the last bad thing that happened to you," half of the responses described interpersonal issues, primarily involving disruptions, separations, and conflict in marriage, love, parental, and other significant relationships. Among those who sought professional and pastoral intervention, i.e. those who could be presumed to be especially distressed, $59 \%$ and $67 \%$ respectively, reported interpersonal problems. The more detailed verbal descriptions provided by participants included conflict-ridden relationships, the desire for more and better communication, understanding, closeness, or physical affection in their relationships, and loss or separation from a lover, spouse, parent, or significant other. These complaints and problems reflect a failure to achieve or maintain desired levels of intimacy and emotional support in relationships. Therefore, it could be reasonably 
concluded that intimate relationships, either when absent or problematic, are related to emotional distress for adults as well as for adolescents.

In addition to the internalizing difficulties discussed above, intimacy could also have implications for externalizing behaviors. Although the literature is sparse with respect to this particular topic, it is reasonable to hypothesize that anti-social behaviors could have a significant negative impact on the formation and maintenance of intimate relationships. In addition, externalizing behaviors could be interpreted as an observable correlate of the interpersonal difficulties experienced as a result of the lack of intimate relationships in that individual's life. One aim of the present study is to explore the possible relationship between measures of intimacy and self-reported externalizing behaviors.

Therefore, the key focus of the present study is to examine the development of a sense of identity and intimacy in an adolescent sample that is considered at-risk for negative developmental outcomes. Gavazzi, Abderson, and Sabatelli (1993) have articulated this need for description of these relations in an adolescent sample. Specifically, they referred to the need to examine adolescent growth and development "in terms of how adjustment indicators are affected by various social contexts, including family systems and peer networks" and the need for future research to be more attentive "to the dyadic qualities of these interpersonal relationships" (p.222). The need for research in this area using an at-risk sample was articulated by Winstanley, Meyers, and Florsheim (2000) as they pointed out that much of the current intimacy research has utilized adult, White heterosexual college students, therefore the need of adolescent samples is great and the need for minority samples is even greater (including those considered at-risk). 
Intimacy and identity: Timing and gender.

Erikson has characterized the challenge of intimacy versus isolation as directly following the psychosocial challenge of identity versus role confusion (1980). As adolescents experience the challenge of developing a sense of identity, the foundations are being laid for the development of a sense of intimacy. Erikson's (1968) theory proposes that it is necessary for the adolescent to experience success in the area of identity development before it is possible to establish a sense of intimacy in early adulthood. Of course, this position is not universally accepted.

Alternate theories can be conflicting. For example, Sullivan's (1953) interpersonal developmental theory postulates that identity and intimacy are approached simultaneously with intimacy issues being a key developmental issue of late childhood and early adolescence with the negotiation of this capacity in the context of "chumships," or intense same-sex friendships. In addition, it has been proposed that the development of a sense of identity and a sense of intimacy involves bi-directional or reciprocal influences (Paul \& White, 1990; Raskin \& Waterman, 1994). For instance, it has been proposed that once the individual has begun to negotiate the challenge of intimacy versus isolation, there may be a need to modify or revisit identity issues that were resolved previously (Paul \& White, 1990). Even when one examines Erikson's $(1968,1980)$ writings regarding identity and intimacy development among females, there are references to the possibility that the process of identity formation may occur simultaneously with, and may be to some degree dependent upon, the development of an intimate relationship with a lifetime partner and raising children together.

Research into timing issues related to identity formation and intimacy have produced inconsistent findings, resulting little more than the theorizing discussed above 
(Adams \& Archer, 1994; Douvan \& Adelson, 1966; Hodgson \& Fischer, 1979; Orlofsky, Marcia, \& Lesser, 1973; Tesch \& Whitbourne, 1982). Considering the inconsistency of these findings, it is important to note that a majority of these studies have utilized young adult samples (i.e., college students), a common occurrence, which may make developmental differences in this domain difficult to document reliably. Young adults may have already begun to weather both challenges and some individuals may have completed their resolution of these developmental tasks. To address questions concerning the timing of the development of a sense of identity or intimacy, it may be better to use an adolescent sample, comprised mostly of middle to late adolescents (i.e., high school students) as in the present study. The issue of timing is important to this population due to the aforementioned need to develop effective interventions specifically targeting issues crucial to their psychosocial development, whether it concerns making life decisions, relationships, alternative lifestyles, etc. In our research, there is a specific need to develop focused interventions for youth considered at-risk for drop-out by their school administration (Ferrer-Wreder et al., 1998; Lorente, 1998).

Gender differences in identity development. Gender differences may be as important as stage of life (age) in the study of identity development and any investigation of timing should also consider gender. It may be necessary to approach some identity issues with the consideration that there may be differences in how females and males resolve identity issues. Reviews of literature on identity development (e.g., Archer \& Waterman, 1988; Ferrer, 1996; Kroger, 1997; Lorente, 1997) have concluded that available evidence is by no means convincing as to whether males and females differ significantly with respect to processes of identity development. Thus, the current literature on gender differences in identity development generates more questions than answers. 
Kroger's (1997) review concluded that there were 56 studies that contributed unique, relevant data regarding gender differences in identity status. Data in these articles were examined for gender differences in four key domains of identity: structure, content, process, and context. The samples utilized for these studies ranged from elementary and high school students to college students and young adults. Regarding the question of structure, which referred to a general style or identity status, the author concluded that these studies provided strong evidence for the statement that there is a "similarity of style that both men and women use to approach identity-defining questions during adolescence and adulthood" (Kroger, 1997, p.750). In the domain of content, or specific issues important in identity-defining decisions, the results were not conclusive for measures using either identity styles or identity domains, regarded as most important. Regarding process, or the timing of changes, the most interesting data were collected from the high school samples, where approximately half of the studies found that movement from less to more mature identity positions was accomplished later for males - a key finding related to timing. Finally, in the area of context, there was some preliminary evidence from the very few studies available that contextual factors may be associated with different modes of identity resolution for males and females (Kroger, 1997). These summaries prompt interesting questions about the exact nature of possible gender differences in the process of identity formation in adolescence. However, no definite conclusions can be drawn due to the lack of appropriately aged samples.

Therefore, empirical questions still remain as to whether or not adolescent males and females differ significantly in how they approach and resolve identity-defining decisions. In addition, the effect that these decisions have on male and female adolescents' adjustment is not completely understood. It appears that the studies utilizing samples of 
adolescents have provided the most intriguing preliminary data on this subject. However, samples of college students have been the primary data source for the majority of studies in this area due to their convenience. Pursuant to questions regarding gender differences in identity development come questions regarding gender differences in the development of a capacity for intimacy.

Gender differences in intimacy development. As mentioned previously, Erikson (1968) suggested that males and females may differ with respect to the ways in which they resolve identity and intimacy issues. If that suggestion is correct, then we may be able to see differences in developmental processes that occur during adolescence. Adolescence is a segment of the life-span when potential gender differences in developmental processes may be examined, whether adolescents are building the foundation for future intimate relationships through negotiation of identity issues or negotiating these key psychosocial issues in a bidirectional, reciprocal manner. In this domain, past examinations of the literature for gender differences have focused on ego identity development (Archer \& Waterman, 1988; Ferrer, 1996; Kroger, 1997; Lorente, 1997). Regarding the literature on the development of a sense of intimacy and possible gender differences, the evidence is by no means convincing as to whether there are gender differences in this process.

There is evidence in support of the position that there are no gender differences (Moore \& Boldero, 1991; Prager, 1983; Raskin, 1985; Tesch \& Whitbourne, 1982; Whitbourne \& Tesch, 1985), as well as in the opposite direction of significant gender differences in the development of intimacy (Bartle-Haring \& Strimple, 1996; Buhrmester \& Furman, 1987; Dyk \& Adams, 1990; Eaton, Mitchell, \& Jolley, 1991; Hodgson \& Fischer, 1979; Schiedel \& Marcia, 1985). It should be noted that many of these studies used late adolescent through young adult population samples, as college student 
populations are readily available to researchers. If we are to adhere to Erikson's characterizations, it would be difficult to document gender differences in intimacy in this stage of development, in that males would be "catching up" to their female counterparts who would have already begun to weather the challenges of both psychosocial issues. There are few studies that have focused on middle to late adolescence, periods that precede and are therefore important to any examination of the developmental course of intimacy.

The five studies that did not find gender differences in intimacy utilized a wide range of theoretical foundations, samples, measures, and analyses (Moore \& Boldero, 1991; Prager, 1983; Raskin, 1985; Tesch \& Whitbourne, 1982; Whitbourne \& Tesch, 1985). Their results could be taken as support for the position that both males and females approach intimacy issues in similar ways. However, there may be reasons to think that these results could be influenced by the specific characteristics of the samples used. For example, there may be age-related and/or maturation-related processes occurring among participants in these samples that could minimize previously existing group differences in adolescence, that were resolved by young adulthood. Support for hypothesis can be found in salient sample characteristics reported by the authors concerning age, intimacy status, and personal characteristics.

The average age of the samples for the studies cited above ranged from 17.5 to 30 years, corresponding to the late adolescent and early adult periods of development. With the exception of Moore and Boldero (1991), all studies utilized samples comprised solely of present or former college students. Any generalization to populations with younger average ages from these results would be speculative. Regarding intimacy status and personal characteristics, Tesch and Whitbourne's (1982) results indicated that (a) a 
significant proportion (67\%) of participants were assigned the intimate/pre-intimate status, (b) all members of the sample had earned bachelor's degrees, and (c) nearly half had some graduate training. In similar study, these authors found that there were "more alumni and fewer college students than would be expected by chance in the high-intimacy statuses of intimate and merger" (Whitbourne \& Tesch, 1985, p.1042). Finally, Prager (1983) reported that there were significant group differences for age, with women in the intimate and pre-intimate statuses older than women in stereotyped relationships.

These findings may indicate that higher levels of education, more mature levels of intimacy, and more life experiences through age may be examples of the individual characteristics and/or life experiences that facilitate the capacity to form intimate relationships (Prager, 1983, Tesch \& Whitbourne, 1982). Considering the Eriksonian model of psychosocial development, this could be seen as evidence that successful resolution of identity and intimacy issues has already occurred for both genders, masking any previously existing group differences. However, these results could also be interpreted as indicating that there are no significant gender differences in the ways in which people resolve intimacy issues.

The studies that did find gender differences also utilized different theoretical foundations, samples, measures, and analytic strategies. There appears, however, to be some evidence to support the hypothesis that differences exist in the way that males and females negotiate and resolve the psychosocial challenge of intimacy versus isolation (Bartle-Haring \& Strimple, 1996; Buhrmester \& Furman, 1987; Dyk \& Adams, 1990; Eaton, Mitchell, \& Jolley, 1991; Hodgson \& Fischer, 1979; Schiedel \& Marcia, 1985). These studies provide evidence that shows significant gender differences in levels of intimacy responses, assessed in a variety of different ways. Hodgson and Fischer's (1979) 
chi-square analysis showed that greater numbers of women than men were classified as belonging to the two highest intimacy statuses (i.e., intimate and preintimate). Similarly, Scheidel and Marcia's (1985) chi-square analysis also revealed significant differences in the distribution of intimacy statuses, with females almost twice as likely as males to be rated as intimate or pre-intimate. A tau analysis was conducted to see if this outcome was a function of age, and this analysis showed that the proportion of females in each status remained the same while the number of men rated highly for intimacy increased as they got older. In the high intimacy statuses, however, there were greater or equal proportions of females, regardless of age. These results suggest an age-related difference between men and women in the timing of the development of intimacy.

Among a younger sample of adolescents, Buhrmester and Furman (1987) found that, with regard to friendships, girls' ratings for the global importance of intimacy and global perceived frequency of intimacy were significantly higher than boys' ratings for these variables. Bartle-Haring and Strimple (1996) found that women reported higher levels of intimacy with their same-sex friends than those reported by men. Gender differences were also evident in Eaton et al.'s (1991) study of relationships, with females reporting a higher need for stimulation and social support, greater commitment to their relationships, greater love for their partners, and higher ratings of good qualities of their partners. These findings suggest that females find issues regarding intimate relationships more salient than do males.

The results of Dyk and Adams' (1990) study were embedded in sex-role orientation due to the nature of their study, however the authors concluded that without looking at sex-role orientation, there was "tentative evidence to confirm some of Erikson's theoretical assumptions that identity predicts intimacy development" (p.108). However, 
there are gender differences concerning sex-role orientation in this framework, specifically where feminine females appeared to develop intimacy at the same time as identity, as predicted for females by Erikson. In contrast, more masculine females and males appear to develop identity prior to the development of intimacy, as predicted for males by Erikson. These findings led the authors to conclude that intimacy was more valued by females than by males.

As previously mentioned, these studies had comparable results despite differences in the conceptualization and the measurement strategies used in the different studies. However, they were by no means conclusive. There may be several reasons why some studies were able to demonstrate differences while the others were not. One of the most obvious differences between these two groups of studies is the average age of the participants. A trend was observed, where the younger the participants included, gender differences were more likely to be found. In addition, there may be experimenter bias in some of these studies, in that it appears that when studies did not hypothesize gender differences, they did not find them. In contrast, when studies hypothesized gender differences, they were more likely to find them. In addition, the conceptualization and operationalization of intimacy varied from study to study. For studies using an interview format, this may be a plausible explanation, because there is considerable subjectivity involved in the process of assigning statuses. Similar to the studies that did not find gender differences, many of the samples from the studies that documented gender differences were composed of college students. Therefore, the previously mentioned idea that higher levels of education selects for samples with specific characteristics and experiences that are necessary to form intimate relationships among either men or women could not be supported with these samples. 
This review of the literature on the development of intimacy and gender differences in related developmental processes provides a useful example suggesting that available evidence regarding gender differences is by no means conclusive. There appears to be ample evidence to support either position. Therefore, we are still left with the empirical question concerning potential significant gender differences in the resolution of the psychosocial challenge of intimacy versus isolation. Although there appears to be a trend among data collected from younger, less mature participants that supports proposed gender differences, data collected from older, more mature participants do not. This finding is by no means impressive, as these results are also often contradictory. Further research is needed regarding this issue using established measures and a longer developmental framework.

In order to obtain a more precise description of the development of intimacy, it is desirable to more thoroughly investigate the early to middle adolescent developmental period, focusing on key issues of identity and intimacy. There is a considerable body of research based on late adolescent and young adult samples that has generated largely contradictory findings. Therefore, it is possible that these samples are too experienced and mature having already resolved the psychosocial challenge of intimacy versus isolation.

These issues leave us with two empirical questions: (a) whether identity and intimacy issues are approached and negotiated by adolescents at different times or simultaneously; and, (b) whether females and males really differ in their development of identity and intimacy. The present study attempts to provide descriptive data to address these issues.

Measuring intimacy. Several types of classification systems have been used to characterize the levels of intimacy that have been achieved or are preferred by youth. With 
regard to the conceptualization of intimacy outlined previously, this study measured intimacy in two ways. The first assessment strategy is derived from the Eriksonian interpretation described above while the second strategy assesses adolescents' attitudes of empathy, trust, commitment, respect, disclosure, and expression of affect toward friends, family, and dating partners. There are two measures of intimacy that are used widely in the available research literature, i.e., the Erikson Psychosocial Stage Inventory (EPSI) and the Intimacy Status Interview (ISI). The current study will use the Erikson Psychosocial Inventory and the Intimacy Assessment Scale, which is a self-report measure developed from the basic framework of the Intimacy Status Interview.

Intimacy Status Interview. Orlofsky et al. (1973) developed an assessment interview that could be used to classify individuals into one of five forms (stages) of the resolution to the intimacy versus isolation challenge: intimate, pre-intimate, pseudointimate, stereotyped, and isolate. This assessment interview is one of the most widely accepted and utilized measures in research on the development of intimacy. The 20 to 30 minute semi-structured interview developed by Orlofsky, et al. evaluates the presence or absence of close interpersonal relationships with peers, as well as the extent of openness, responsibility, closeness, mutuality, and commitment in their most significant interpersonal relationships. This interview attempts to obtain a comprehensive picture of these social relationships that is very helpful to understanding their development and dynamics.

The first portion of the interview presents questions concerning the nature of the participants' friendships. The questions probe how close they feel with same-sex friends, whether they can share personal problems and worries with them, and if they feel they have an insight into and an understanding of how their friends feel. Items also ask if their relationships with friends are enduring and if they have lived with the same friends for 
several years or constantly change roommates. Finally, items ask what friendship means to the participants. The second portion of the interview deals with opposite-sex relationships and asks questions along the same lines. However, they are more detailed and include items concerning the extent of dating experiences (i.e., if they are dating presently or had ever dated one person exclusively). The second part of the interview also assesses feelings of openness, closeness, jealousy, possessiveness, degree of commitment, sexual activity, ability to express and resolve angry feelings, and insights into their own needs, dating partners' needs, and problems in the relationship. Based on the participant's responses to these questions, scores are assigned for same-sex relationships and for opposite-sex relationships, as well as for an aggregate score. Although the development and validation of this measure was originally conducted using a male sample, subsequent investigations have also used females with success. In addition, due to the subjectivity of the assignment of statuses, Orlofsky (1993) recommends that two or more interviewers and raters be used.

The Orlofsky et al. (1973) interview was validated by using the unpublished, pioneer measure of intimacy, the Yufit Intimacy-Isolation Scale (Yufit, 1956), which classifies the individual into either an intimate or isolate category. When comparing the intimacy status score to the score yielded from the Yufit Intimacy-Isolation Scale, Orlofsky et al. (1973) found that, as expected, intimate and pre-intimate participants had significantly higher scores than pseudo-intimate and stereotyped subjects, who had significantly higher scores than isolate subjects. Isolate subjects scored lowest on the intimacy scale and highest on the isolation subscale. These results indicated that there was a substantial degree of agreement between the two measures. While Orlofsky et al. noted that the Yufit scale uses different criteria for assignment to either classification, there still 
was significant agreement between the two measures. These results were taken as support for the validity of the constructs developed by Orlofsky et al.

In addition, intimacy may be conceptualized as the capacity to perceive and respond to another's needs. Therefore, Orlofsky (1976) examined the validity of the intimacy statuses by investigating their relationships to a measure of "partner perception". Participants in this study were friendship dyads. Orlofsky (1976) measured the degree of mutual knowledge and understanding in dyads by determining their ability to correctly predict the other's responses to a personality and attitude inventory. As hypothesized, participants who were intimate (including those assigned pre-intimate status) were more accurate in their predictions than those who were less intimate (pseudo-intimate and stereotyped), who were in turn more accurate than the isolates. These findings were consistent with the previous study's findings and were taken as providing further support for Orlofsky's theory of intimacy statuses.

This interview is very labor intensive for both the researcher and the participant. It is a challenging measure to use in all research situations. The Intimacy Assessment Scale (IAS) to be used in this study is a self-report measure that is based on the Intimacy Status Interview. The questions are designed to measure the degree of intimacy reported in relationships with friends, family members, and dating partners in a manner consistent with the interview. However it uses a self-report, survey format.

The Aims of the Study

To summarize, the first aim of this study was to examine whether there were significant relations between identity, intimacy, and adjustment and to test for any gender differences in a sample of adolescents considered at-risk for problem behaviors by their school district. Specifically, this study investigated empirically the role of identity (i.e., 
exploration and commitment) and intimacy as predictors of adjustment difficulties, including internalizing and externalizing difficulties. A sample of approximately 120 high school students (age range 14 to 19 years) from an alternative high school established for at-risk students were interviewed. The test battery comprised of a demographic questionnaire, adjustment measures (i.e., the Youth Self-Report), an Eriksonian measure of identity (the Ego-Identity Process Questionnaire), and intimacy measures (i.e., the Erikson Psychosocial Inventory Scale's intimacy subscale and the Intimacy Assessment Scale). Results are discussed in terms of theoretical and practical implications, including using the results for the development of interventions. 


\section{CHAPTER 2: METHODS}

\section{Participants}

A total of 120 urban high school students participated in this study (96 males, 64 females; age range 14 to 19 years). Key demographic characteristics of the sample are summarized in Table 1. This school is an alternative high school established by Dade County Public Schools for students identified as being "at risk" for a multitude of problem behaviors and adverse outcomes. The sample was predominately Hispanic $(51.2 \%, n=83)$ and African American (24.7\%, $n=40)$, with $15.4 \%(n=25)$ identifying themselves as nonHispanic whites and $8.6 \%(n=14)$ as identifying themselves as Other race/ethnicity. The Academy for Community Education (ACE) in Coral Gables, Florida is an alternative high school aimed at drop out prevention. The mission of ACE is to, "...educate students who are having difficulties in school and students who have dropped out and returned to school" (Academy for Community Education, 1995-1996, p. 1). The socio-demographic and individual risk factors that many of these students experience include minority group status, low socio-economic conditions, teenage parenthood, and/or below average academic performance in previous high school settings. This sample of students was targeted because these types of students are highly prevalent in many large metropolitan areas and various schools throughout the country attempt to serve this type of population. Thus, an effective intervention geared towards this population could possibly enhance the impact of the services provided by schools, preventing school dropout and improving these students' lives in general. 
Table 1

Summary of sample demographics

Frequency Percent

Gender

$\begin{array}{lll}\text { Male } & 96 & 58.5 \\ \text { Female } & 64 & 39.0\end{array}$

Grade

$\begin{array}{lll}\text { Grade } 9 & 24 & 14.6 \\ \text { Grade } 10 & 55 & 33.5 \\ \text { Grade } 11 & 50 & 30.5 \\ \text { Grade } 12 & 31 & 18.9\end{array}$

Age

14 Years

7

4.3

15 Years

44

26.8

16 Years

50

30.5

17 Years

42

25.6

18 Years

14

8.5

19 Years

3

1.8

Ethnicity

White, non-Hispanic 24

14.6

African-American

40

24.4

Hispanic

83

50.6

Other

13

7.9

$N=160$ Missing cases $=4(2.4 \%)$ 


\section{Measures}

Ego Identity Process Questionnaire (EIPQ). The EIPQ (Balistreri, BuschRossnagel, \& Geisinger, 1995) is a self-report questionnaire that is administered in a standardized paper and pencil format. This instrument is designed to assess exploration and commitment in several domains (i.e., moral, personal, and interpersonal areas). Participants are asked to make 32 separate statements using a 5-point Likert scale. These statements are thought to be characteristic of individuals who have explored or committed to various principles, lifestyles, and/or beliefs. The EIPQ yields several exploration and commitment scores in ideological and interpersonal domains. The ideological domain consists of questions about politics, occupation, religion, and world views. The interpersonal domain consists of questions about family, friends, dating and sex roles. Scores for this questionnaire are determined as follows: (1) Interpersonal Domain, Exploration and Ideological Domain Exploration, 8 items each, resulting in a minimum score of 8 and a maximum score of 40 per domain, and (2) Interpersonal Domain, Commitment and Ideological Domain Commitment, 8 items each, resulting in a minimum score of 8 and a maximum score of 40 per domain. Internal reliability for the EIPQ (Balistreri, Busch-Rossnagel, \& Geisinger, 1995) was acceptable. The exploration and commitment alpha coefficients (Cronbach's alpha) were .76 and .75, respectively. Testretest coefficients were .91 for exploration and .78 for commitment. In the current sample, internal consistency alpha coefficients were .64 for exploration and .53 for commitment.

Eriksonian Psychosocial Stage Inventory (EPSI). The EPSI (Rosenthal, Gurney, \& Moore, 1981) is a 72-item self-report survey that includes six subscales corresponding to Erikson's first six stages of psychosocial development. For the purposes of this study, the 12 items corresponding to the intimacy portion of the EPSI were used to assess 
participants' level of intimacy. Six of the items represent successful resolutions and six of the items represent unsuccessful resolutions of the psychosocial challenge of intimacy versus isolation. Items were developed by utilizing key words and statements from Erikson's characterizations of these stages. These items were screened for ambiguity and face validity by the authors and were simplified as much as possible. The measure was designed for use with a sample that was age 13 or above. Responses are made according to a 5-point Likert scale ranging from hardly ever true (1) to almost always true (5), yielding a continuous total score. This subscale yields a minimum score of 12 and a maximum score of 60 . The EPSI can be administered individually or in a group format.

A pilot sample of 97 high school adolescents was utilized for analysis of the original items. For this sample, there was an additional response category of "don't understand". Items that had high responses in this category were removed. In addition, items that showed poor item-total correlations in each subscale were also removed in order to maximize internal reliability. Finally, the twelve items that showed the highest item-total correlations were retained for use in the final version of the EPSI.

Rosenthal et al. (1981) reported the reliability and validity of this measure using a high school sample of 622 adolescents. They reported an alpha of .63 for the intimacy subscale, as well as satisfactory construct validity. Construct validity was established by comparing EPSI scores to scores obtained on the PSM. Greenberger and Sorensen (1964) developed the PSM as a self-report attitude inventory designed to measure psychosocial maturity. Conceptual links between the two measures were said to be strong enough to predict relationships between the subscales of each of the measures. Accordingly, there were "encouragingly high correlations with relevant subscales of the PSM, providing some 
measure of construct validity" (Rosenthal et al., 1981, p.531). For the current sample, the internal consistency coefficient was .63.

Intimacy Assessment Scale (IAS). The IAS (Berman, Lorente, Martinez, \& Kurtines, 1997) is a 78-item question pencil and paper measure adapted from Orlofsky, Marcia and Lesser's (1973) and Archer's (1982) interview measures of the construct of intimacy. It consists of three domains (family, friends, and dating relationship) in which attitudes toward empathy, trust, commitment, respect, disclosure, and expression of affect, are explored. The measure yields a continuous intimacy score in the three domains with a minimum score of 26 and a maximum score of 130 , as well as an overall intimacy score for a minimum total of 78 and a maximum total score of 390 . Internal reliability coefficients (Cronbach's alpha) for the IAS were reported as .90. For the current sample, the internal reliability coefficient was .89 .

Youth Self-Report (YSR). The Youth Self-Report (YSR) was administered in the standard paper and pencil format for individuals between the ages of 11 and 18 . The participant's knowledge of their own behavior and emotions makes them potentially important contributors to the assessment process. Adolescents are cognitively equipped to provide reports of their own feelings and behavior across situations (Achenbach, 1991). Youths were asked to rate themselves on 117 problem items. A 0-1-2 scale was used to state how true the item is within the past six months. The checklist requires a fifth grade reading level, but can be read to respondents who do not meet this requirement. Scoring of the Youth Self-Report provided scores for internalizing and externalizing behaviors. Achenbach (1991) has reported a test-retest correlation of .80 for internalizing and .81 for externalizing self-reported behavior. Findings on reliability and validity warrant 
considerable confidence in the syndrome and global scale scores as measures of problem patterns.

\section{Procedures}

All students in the school (ACE) were individually asked to participate in this study. Most students were eager to participate because they were allowed time out of class to complete the measures. Students were also offered other small incentives, such as snacks, drinks, or candy. All willing students were selected for participation. Participants were included in the study if they expressed a willingness to complete all of the assessments and to provide informed consent. Students who did not wish to participate were excluded, however only one student expressed a desire to be excluded in three years of data collection (Lorente, 2002).

Data Analyses

The primary research goal of this study was to empirically investigate the domains of exploration and commitment (as related to identity development) and levels of intimacy as predictors of internalizing and externalizing behavioral problems. Gender differences in identity development (specifically exploration and commitment), levels of intimacy, and adjustment were also examined. This section describes the analyses that were performed to test the following hypotheses:

Hypothesis 1: With regard to gender, males will report significantly higher levels of exploration than females and females will report significantly higher levels of intimacy than males. 
Hypothesis 2: There will be a significant positive correlation between EIPQ exploration scores and YSR internalizing and externalizing scores, meaning that adolescents actively exploring to develop their identity and not yet committed are more likely to experience emotional and social turmoil and more likely to experiment with acting out and/or anti-social behaviors.

Hypothesis 3: There will be a significant negative correlation between EIPQ commitment scores and YSR internalizing and externalizing scores, meaning that adolescents who have started the process of commitment in identity formation are less likely to feel depressed or withdrawn and less likely to engage in acting out or anti-social behaviors.

Hypothesis 4: There will be a significant negative correlation between EPSI and IAS intimacy scores and YSR internalizing and externalizing scores, meaning that adolescents who report higher levels of intimacy are less likely to be acting out with antisocial behavior or to feel withdrawn or depressed.

Hypothesis 5: Identity measures will account for a greater proportion of the variance in adjustment scores than will measures of intimacy, meaning that matters having to do with identity formation are more salient to the adolescent stage of development than are intimacy issues.

In order to better describe our sample, the first step in analysis was a descriptive analysis of key demographic variables and determination of the distributions of those variables. To test for significant gender differences, one-way MANOVAs were performed on identity and intimacy scores, as well as internalizing and externalizing scores. Pearson $r$ correlations were calculated to look for associations between sets of the predictor 
variables, as well as between the predictor variables and outcome variables. Finally, to test whether levels in identity and intimacy predict adjustment, three sets of hierarchical multiple regression analyses were conducted to determine if identity or intimacy measures accounted for a significant proportion of variance in the scores for internalizing or externalizing symptoms. Gender and other demographic variables were entered first in the equations, as it is important to control for any gender effects so that the unique amount of variance accounted for by both identity and intimacy on adjustment could be determined.

It was hypothesized that identity measures would account for a significantly greater amount of variance in adjustment scores than that accounted for by the measures of intimacy. Consequently, three sets of hierarchical regressions were performed. In the first set, internalizing symptoms were examined using identity and intimacy scores, and in the second set, externalizing symptoms were examined using identity and intimacy scores. The third set used a three step model in which the order of entry for the identity and intimacy variables was alternated in the second and third steps. If the models demonstrated that identity scores accounted for a more significant amount of additional variance in internalizing and externalizing scores, then we could take that as evidence that identitydefining issues are more important to adjustment within this sample than the other variables, including intimacy scores. If the models demonstrate that intimacy scores accounted for a more significant amount of additional variance in adjustment scores, then we could take that as evidence that intimacy issues are more important to adjustment within this sample than the other variables, including identity scores. If neither of these variables accounts for a significant proportion of additional variance beyond that accounted for by the other variables, then that may suggest bi-directional or reciprocal influences between the two variables. 


\section{CHAPTER 3: RESULTS}

Hypothesis 1: It was hypothesized that (a) males would report significantly higher levels of identity exploration than females and (b) females would report significantly higher levels of intimacy than males. Tables 2 and 3 present the means and standard deviations of key variables and descriptive statistics for between group differences by gender. The results of the first MANOVA examining gender differences for key identity and intimacy variables is summarized in Table 4. The Pillai-Bartlett multivariate test statistic indicated significant group differences in mean levels of these variables $(V=.096, F=3.004,4 / 113$ df, $p<.021$ ). Univariate tests for individual variables revealed significant gender differences for identity exploration, $F(1,117)=11.46, p<.001, \eta^{2}=.09$, with females reporting significantly higher scores than males. However, there were no significant differences in mean levels of commitment $F(1,117)=.362$, NS, $\eta^{2}=.003$, EPSI intimacy $F(1,117)=.000, \mathrm{NS}, \eta^{2}=.000$, or IAS intimacy $F(1,117)=.175, \mathrm{NS}, \eta^{2}=.002$

Table 4 also presents the results of the second MANOVA examining gender differences for key adjustment variables. The Pillai-Bartlett multivariate test statistic indicated significant group differences by gender in mean levels of these variables $(V=$ $.134, F=9.052,2 / 117 \mathrm{df}, p<.001)$. The univariate tests for individual variables revealed significant gender differences in mean levels of internalizing symptoms, $F(1,119)=$ $16.264, p<.001, \eta^{2}=.121$; but no significant difference for externalizing $F(1,119)=$ $.249, \mathrm{NS}, \eta^{2}=.002$. While, females reported significantly higher scores for internalizing symptoms, males and females did not differ significantly in their reports of externalizing symptoms (see Table 3 ). 
Table 2

Means and Standard Deviations of Key Variables

\begin{tabular}{lccc}
\hline Study Variables & $N$ & Mean & \multicolumn{2}{c}{ S.D. } \\
\cline { 2 - 4 } Age & 160 & 16.13 & 1.11 \\
Exploration & 156 & 51.32 & 8.29 \\
Commitment & 157 & 36.00 & 7.27 \\
EPSI Intimacy & 158 & 42.29 & 7.08 \\
IAS Intimacy & 120 & 270.96 & 33.67 \\
Internalizing & 121 & 14.04 & 8.17 \\
Externalizing & 122 & 18.63 & 8.65 \\
\hline
\end{tabular}


Table 3

Descriptive statistics for between variable gender differences

\begin{tabular}{|c|c|c|c|c|}
\hline & Gender & $\mathrm{N}$ & Mean & S.D. \\
\hline \multirow[t]{3}{*}{ Exploration } & Male & 66 & 49.58 & 8.38 \\
\hline & Female & 52 & 54.58 & 7.42 \\
\hline & Total & 118 & 51.78 & 8.32 \\
\hline \multirow[t]{3}{*}{ Commitment } & Male & 66 & 55.14 & 7.02 \\
\hline & Female & 52 & 55.94 & 7.49 \\
\hline & Total & 118 & 55.49 & 7.21 \\
\hline \multirow[t]{3}{*}{ EPSI Intimacy } & Male & 66 & 42.86 & 7.36 \\
\hline & Female & 52 & 42.85 & 6.62 \\
\hline & Total & 118 & 42.86 & 7.01 \\
\hline \multirow[t]{3}{*}{ IAS Intimacy } & Male & 66 & 271.27 & 37.66 \\
\hline & Female & 52 & 268.69 & 26.62 \\
\hline & Total & 118 & 270.14 & 33.15 \\
\hline \multirow[t]{3}{*}{ Internalizing } & Male & 68 & 11.63 & 7.41 \\
\hline & Female & 52 & 17.35 & 8.05 \\
\hline & Total & 120 & 14.11 & 8.17 \\
\hline \multirow[t]{3}{*}{ Externalizing } & Male & 68 & 18.40 & 8.83 \\
\hline & Female & 52 & 19.19 & 8.42 \\
\hline & Total & 120 & 18.74 & 8.63 \\
\hline
\end{tabular}


Table 4

Tests for gender differences

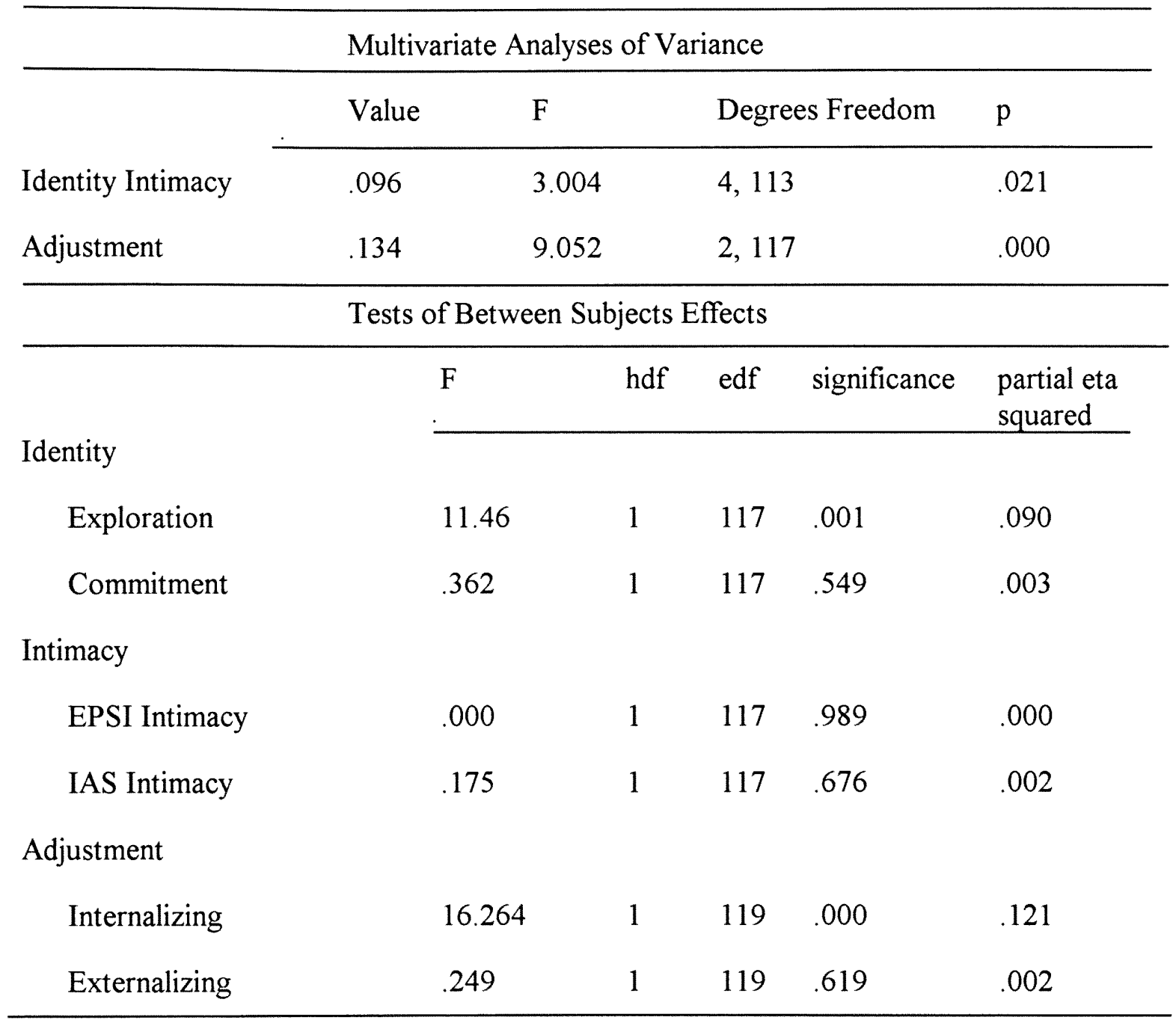


Therefore, hypothesis 1 received only modest support. With regard to mean levels of identity and intimacy, females reported higher levels of identity exploration than males, but males and females did not report significant differences in levels of self-reported intimacy. In the area of domain adjustment, females also reported higher levels of internalizing symptoms. However, males and females did not differ significantly in mean levels of self-reported externalizing symptoms. It seems that higher levels of female exploration for identity development, rather than levels of intimacy development, may be related to higher levels of internalizing symptoms. The data did not reveal significant relations among intimacy development, gender, and adjustment.

Hypotheses 2 through 4: Pearson correlations among key variables measured for this study are presented in Table 5. Hypothesis 2 stated there would be a significant positive correlation between EIPQ exploration scores and YSR internalizing and externalizing scores. The Pearson correlations identified a significant positive correlation between EIPQ exploration scores and YSR internalizing symptoms, $(r=.31, p<.001)$, but not between EIPQ exploration scores and YSR externalizing symptoms $(r=.026, p<$ .776). Therefore, Hypothesis 2 was only partially supported. Hypothesis 3 stated there would be significant negative correlations between EIPQ commitment scores and YSR internalizing and externalizing scores. Pearson correlations presented in Table 5 indicated that identity commitment was not significantly associated with either YSR internalizing $(r$ $=-.047, p<.607)$ or externalizing scores $(r=.071, p<.436)$. Therefore, Hypothesis 3 was not supported. 
Table 5

Pearson correlations among key variables

Adjustment

Internalizing Externalizing

Identity

Exploration

Pearson Correlation

.310

.026

Sig (2-tailed)

.001

.776

$\mathrm{N}$

119

120

Commitment

$\begin{array}{lll}\text { Pearson Correlation } & -.047 & .071 \\ \text { Sig (2-tailed) } & .607 & .436 \\ \mathrm{~N} & 120 & 121\end{array}$

Intimacy

EPSI

Pearson Correlation

$-.077 \quad .060$

Sig (2-tailed)

.401

.512

$\mathrm{N}$

120

121

IAS
Pearson Correlation
$-.220$
$-.146$
Sig (2-tailed)
.017
.115
$\mathrm{N}$
117
118 
Hypothesis 4 stated there would be a significant negative correlation among EPSI and IAS intimacy scores and YSR internalizing and externalizing scores. Pearson correlations shown in Table 5 reveal that intimacy as measured by IAS scores was significantly negatively related to internalizing symptoms $(r=-.220, p<.05)$, but it was not correlated significantly with to YSR externalizing symptoms $(r=-.146, p<.115)$. In contrast, EPSI scores were not correlated significantly with either YSR internalizing $(r=-$ $.077, p<.401)$ or YSR externalizing scores $(r=.060, p<.512)$. Therefore, hypothesis 4 was only partially supported.

Hypothesis 5: This hypothesis stated that identity measures would account for a greater proportion of the variance in adjustment scores compared to the proportion accounted for by measures of intimacy. To examine if measures of identity or intimacy accounted for more variance in indices of adjustment, three sets of hierarchical multiple regression (HMR) analyses were conducted (with gender, age, and grade level entered in the first step as covariates). Results of HMR analyses are summarized in Tables 6 through 11. Data regarding changes in $F$ statistics for the regression equations are summarized in Table 12 .

Internalizing Symptoms. In the first set, internalizing symptoms were regressed upon identity and intimacy scores. Table 6 summarizes the results for the regression equation regressing YSR internalizing symptoms upon measures of identity development. Variables were entered in two steps: (a) the control variables (age, gender, grade), (b) the identity variables (exploration and commitment). Variables entered at step one accounted 
Table 6

Regression Table for Identity Scores Predicting YSR Internalizing Scores

\begin{tabular}{lllllll}
\hline & & $\begin{array}{l}\text { Sum of } \\
\text { Squares }\end{array}$ & df & $\begin{array}{l}\text { Mean } \\
\text { Square }\end{array}$ & F & Sig. \\
\cline { 3 - 7 } Model 1 & Regression & 1113.410 & 3 & 371.137 & 6.200 & .001 \\
& Residual & 6823.683 & 114 & 59.857 & & \\
Model 2 & Regression & 1637.702 & 5 & 327.540 & 5.824 & .000 \\
& Residual & 6299.392 & 112 & 56.245 & & \\
& Total & 7937.093 & 117 & & & \\
\hline
\end{tabular}

\begin{tabular}{|c|c|c|c|c|}
\hline & & Beta & $\mathrm{t}$ & Sig. \\
\hline \multirow[t]{4}{*}{ Model 1} & (Constant) & & 1.846 & .067 \\
\hline & Gender & .346 & 3.813 & .000 \\
\hline & Grade & -.082 & -.635 & .527 \\
\hline & Age & -.063 & -.486 & .628 \\
\hline \multirow[t]{6}{*}{ Model 2} & (Constant) & & 1.188 & .237 \\
\hline & Gender & .269 & 2.936 & .004 \\
\hline & Grade & -.101 & -.796 & .428 \\
\hline & Age & -.086 & -.683 & .496 \\
\hline & Exploration & .270 & 3.028 & .003 \\
\hline & Commitment & -.016 & -.190 & .850 \\
\hline
\end{tabular}


Table 12

Change Statistics for Regression Analyses

\begin{tabular}{llll} 
& \multicolumn{2}{l}{ Change Statistics } \\
\hline & & Internalizing \\
R Square $\quad$ F Change & df1 & df 2 & Sig. F Change
\end{tabular}

Step 1

$\begin{array}{llllll}\text { Age, Gender, Grade } & .140 & 6.200 & 3 & 114 & .001\end{array}$

Step 2

$\begin{array}{llllll}\text { Identity } & .066 & 4.661 & 2 & 112 & .011\end{array}$

Step 1
Age, Gender, Grade .154
6.859
$\begin{array}{lll}3 & 113 \quad .000\end{array}$

Step 2

\begin{tabular}{cccccc} 
Intimacy & .040 & 2.755 & 2 & 111 & .068 \\
\hline \multicolumn{3}{c}{ Externalizing } \\
\hline
\end{tabular}

Step 1

$\begin{array}{llllll}\text { Age, Gender, Grade } & .005 & .179 & 3 & 115 \quad .910\end{array}$

Step 2

$\begin{array}{llllll}\text { Identity } & .007 & .410 & 2 & 113 & .665\end{array}$

Step 1
Age, Gender, Grade $\quad .005$
.201
$\begin{array}{ll}3 & 114 \\ .896\end{array}$

Step 2

$\begin{array}{llllll}\text { Intimacy } & .039 & 2.270 & 2 & 112 & .108\end{array}$


for a significant amount of variance, $R^{2}=.140$, yielding a significant equation, $F(3,114)=$ $6.200, p<.001$, with gender reaching statistical significance, $\beta=.346, t(3,114)=3.813, p$ $<.001$. Identity variables entered at step two accounted for a significant amount of additional variance, $\Delta R^{2}=.066$, which yielded a significant equation, $F(5,112)=5.824, p$ $<.001$, in which two of the beta weights reached statistical significance, gender, $\beta=.269$, $t(5,112)=2.936, p<.01$ and identity exploration, $\beta=.270, t(5,112)=3.028, p<.01$. For internalizing scores, these results indicated that age, gender, and grade accounted for $14 \%$ of the variance and identity status accounted for an additional $6.6 \%$ of the variance, meaning that a total of $20.6 \%$ of the variance in internalizing scores was accounted for by gender and identity status, with gender and exploration scores being the significant predictor variables.

Table 7 summarizes the results for the regression equation regressing YSR internalizing symptoms upon levels of intimacy, as measured by the IAS and EPSI. Variables were entered in two steps: (a) the control variables (age, gender, grade), (b) the intimacy variables (IAS intimacy and EPSI intimacy). Variables entered in step one accounted for a significant amount of variance, $\Delta R^{2}=.154$, yielding a significant equation, $F(3,113)=6.859, p<.001$, in which gender reached statistical significance, $\beta=.370$, $t(3,113)=4.084, p<.001$. Intimacy variables entered in step two accounted for a significant amount of additional variance, $\Delta R^{2}=.040$, and yielded a significant equation, $F$ $(5,111)=5.345, p<.000$, in which two of the beta weights for the equation reached statistical significance, gender, $\beta=.359, t(5,111)=4.016, p<.001$, and IAS intimacy, $\beta=$ $.213, t(5,111)=-2.336, p<.05$. For internalizing scores, these results indicated that age, 


\section{Table 7}

Regression Table for Intimacy Scores Predicting YSR Internalizing Scores

\begin{tabular}{|c|c|c|c|c|c|c|}
\hline & & $\begin{array}{l}\text { Sum of } \\
\text { Squares }\end{array}$ & $\mathrm{df}$ & $\begin{array}{l}\text { Mean } \\
\text { Square }\end{array}$ & $\mathrm{F}$ & Sig. \\
\hline \multirow[t]{3}{*}{ Model 1} & Regression & 1153.154 & 3 & 384.385 & 6.859 & .000 \\
\hline & Residual & 6332.710 & 113 & 56.042 & & \\
\hline & Total & 7485.863 & 116 & & & \\
\hline \multirow[t]{4}{*}{ Model 2} & Regression & 1452.667 & 5 & 290.533 & 5.345 & .000 \\
\hline & Residual & 6033.196 & 111 & 54.353 & & \\
\hline & Total & 7485.863 & 116 & & & \\
\hline & & Beta & $\mathrm{t}$ & Sig. & & \\
\hline \multirow[t]{4}{*}{ Model 1} & (Constant) & & 1.541 & .126 & & \\
\hline & Gender & .370 & 4.084 & .000 & & \\
\hline & Grade & -.048 & -.375 & .708 & & \\
\hline & Age & -.064 & -.490 & .625 & & \\
\hline \multirow[t]{6}{*}{ Model 2} & (Constant) & & 2.366 & .020 & & \\
\hline & Gender & .359 & 4.016 & .000 & & \\
\hline & Grade & -.027 & -.211 & .833 & & \\
\hline & Age & -.078 & -.600 & .550 & & \\
\hline & EPSI Intimacy & .053 & .565 & .573 & & \\
\hline & IAS Intimacy & -.213 & -2.336 & .021 & & \\
\hline
\end{tabular}


gender, and grade accounted for $15.4 \%$ of the variance and intimacy status accounted for an additional $4.0 \%$ of the variance, meaning that a total of $19.4 \%$ of the variance in YSR internalizing scores was accounted for by age, gender, grade, and intimacy status, with gender and IAS Intimacy identified as significant predictors. Hypothesis 5 stated that identity measures would account for a greater amount of the variance in adjustment scores than would measures of intimacy. The hypothesis was partially supported in the area of internalizing scores, in that identity status accounted for a statistically significant amount of variance that was greater than the amount of variance explained by IAS Intimacy scores.

Externalizing Symptoms. Table 8 presents the results for the regression equation regressing YSR externalizing symptoms upon levels of identity development. Variables were entered in two steps: (a) the control variables (age, gender, grade), (b) the identity variables (exploration and commitment). Variables entered at step one accounted for a nonsignificant amount of variance, $\Delta R^{2}=.005$, resulting in a nonsignificant equation, $F$ $(3,115)=.179, p<.910$, in which none of the beta weights reached statistical significance. Identity variables entered in step two accounted for a nonsignificant amount of additional variance, $\Delta R^{2}=.007$, resulting in a nonsignificant equation, $F(5,113)=.271, p<.928$, in which none of the beta weights reached statistical significance.

Table 9 summarizes the results for the regression equation regressing YSR externalizing symptoms upon levels of intimacy. Variables were entered in two steps: (a) the control variables (age, gender, grade), (b) the intimacy variables (IAS intimacy and EPSI intimacy). Variables entered in step one accounted for a nonsignificant amount of 
Table 8

Regression Table for Identity Variables Predicting YSR Externalizing Scores

\begin{tabular}{|c|c|c|c|c|c|c|}
\hline & & $\begin{array}{l}\text { Sum of } \\
\text { Squares }\end{array}$ & $\mathrm{df}$ & $\begin{array}{l}\text { Mean } \\
\text { Square }\end{array}$ & $\mathrm{F}$ & Sig. \\
\hline \multirow[t]{3}{*}{ Model 1} & Regression & 40.433 & 3 & 13.478 & .179 & 910 \\
\hline & Residual & 8646.862 & 115 & 75.190 & & \\
\hline & Total & 8687.294 & 118 & & & \\
\hline \multirow[t]{4}{*}{ Model 2} & Regression & 102.756 & 5 & 20.551 & .271 & .928 \\
\hline & Residual & 8584.538 & 113 & 75.969 & & \\
\hline & Total & 8687.294 & 118 & & & \\
\hline & & Beta & $\mathrm{t}$ & Sig. & & \\
\hline \multirow[t]{4}{*}{ Model 1} & (Constant) & & 1.468 & .145 & & \\
\hline & Gender & .068 & .692 & .490 & & \\
\hline & Grade & -.030 & -.217 & .828 & & \\
\hline & Age & .009 & .062 & .950 & & \\
\hline \multirow[t]{6}{*}{ Model 2} & (Constant) & & .954 & .342 & & \\
\hline & Gender & .057 & .552 & .582 & & \\
\hline & Grade & -.051 & -.363 & .717 & & \\
\hline & Age & .011 & .078 & .938 & & \\
\hline & Exploration & .033 & .329 & .743 & & \\
\hline & Commitment & .082 & .861 & .391 & & \\
\hline
\end{tabular}


Table 9

Regression Table for Intimacy Variables Predicting YSR Externalizing Scores

\begin{tabular}{|c|c|c|c|c|c|c|c|}
\hline & & $\begin{array}{l}\text { Sum of } \\
\text { Squares }\end{array}$ & $\mathrm{df}$ & $\begin{array}{l}\text { Mean } \\
\text { Square }\end{array}$ & & $\mathrm{F}$ & Sig. \\
\hline \multirow[t]{3}{*}{ Model 1} & Regression & 44.241 & 3 & 14.747 & & .201 & .896 \\
\hline & Residual & 8367.632 & 114 & 73.400 & & & \\
\hline & Total & 8411.873 & 117 & & & & \\
\hline \multirow[t]{4}{*}{ Model 2} & Regression & 370.160 & 5 & 74.032 & & 1.031 & .403 \\
\hline & Residual & 8041.713 & 112 & 71.801 & & & \\
\hline & Total & 8411.873 & 117 & & & & \\
\hline & & Beta & $\mathrm{t}$ & & Sig. & & \\
\hline \multirow[t]{4}{*}{ Model 1} & (Constant) & & 1.268 & & .207 & & \\
\hline & Gender & .074 & .750 & & .455 & & \\
\hline & Grade & -.003 & -.023 & & .982 & & \\
\hline & Age & .007 & .051 & & .959 & & \\
\hline \multirow[t]{6}{*}{ Model 2} & (Constant) & & 1.825 & & .071 & & \\
\hline & Gender & .062 & .636 & & .526 & & \\
\hline & Grade & .007 & .049 & & .961 & & \\
\hline & Age & -.026 & -.187 & & .852 & & \\
\hline & EPSI Intimacy & .149 & 1.459 & & .147 & & \\
\hline & IAS Intimacy & -.192 & -1.949 & & .054 & & \\
\hline
\end{tabular}


variance, $\Delta R^{2}=.005$, resulting in a nonsignificant equation, $F(3,114)=.201, p<.896$, in which none of the beta weights reached statistical significance. Intimacy variables entered in step two accounted for a nonsignificant amount of additional variance, $\Delta R^{2}=.039$, resulting in a nonsignificant equation, $F(5,112)=1.031, p<.403$, in which IAS intimacy approached but did not reach statistical significance, $\beta=-.192, t(5,112)=-1.949, p<$ 054. These data did not support the hypothesis that identity scores would account for a greater amount of variance in YSR externalizing scores, since neither identity nor intimacy scores significantly predicted YSR externalizing scores.

Table 10 summarizes the results for the regression equation regressing YSR internalizing symptoms upon levels of intimacy and identity. Variables were entered in three steps: (a) the control variables (age, gender, grade), (b) the intimacy variables (IAS intimacy and EPSI intimacy) and (c) identity variables (EIPQ exploration and commitment). Variables entered in step one accounted for a significant amount of variance, $\Delta R^{2}=.154$, resulting in a significant equation, $F(3,112)=6.785, p<.001$, in which the beta weight for gender reached statistical significance $\beta=.370, t(3,112)=$ $4.068, p<.001$. Intimacy variables entered in step two accounted for a nonsignificant amount of additional variance, $\Delta R^{2}=.040$, yet the regression equation remained significant, $F(5,110)=5.296, p<.001$, in which IAS intimacy reached statistical significance, $\beta=-.213, t(5,110)=-2.330, p<.05$. In addition, the beta weight for gender was statistically significant $\beta=.360, t(5,110)=4.005, p<.001$. Identity variables entered in step three accounted for a nonsignificant amount of additional variance, $\Delta R^{2}=.036$, yet the regression equation remained significant, $F(7,108)=4.598, p<.001$, in which EIPQ 
Table 10

Regression Table for Intimacy and Identity Variables Predicting YSR Internalizing Scores

\begin{tabular}{lllllll}
\hline & & $\begin{array}{l}\text { Sum of } \\
\text { Squares }\end{array}$ & df & $\begin{array}{l}\text { Mean } \\
\text { Square }\end{array}$ & F & Sig. \\
\cline { 3 - 7 } Model 1 & Regression & 1150.678 & 3 & 383.559 & 6.785 & .000 \\
& Residual & 6331.287 & 112 & 56.529 & & \\
Model 2 & Regression & 1451.668 & 5 & 290.334 & 5.296 & .000 \\
& Residual & 6030.297 & 110 & 54.821 & & \\
& Total & 7481.966 & 115 & & & \\
Model 3 & Regression & 1717.801 & 7 & 245.400 & 4.598 & .000 \\
& Residual & 5764.165 & 108 & 53.372 & & \\
\hline
\end{tabular}


Table 10 continued

$\underline{\text { Regression Table for Intimacy and Identity Variables Predicting YSR Internalizing Scores }}$

\begin{tabular}{|c|c|c|c|c|}
\hline & & Beta & $\mathrm{t}$ & Sig. \\
\hline \multirow[t]{4}{*}{ Model 1} & (Constant) & & 1.539 & .127 \\
\hline & Gender & .370 & 4.068 & .000 \\
\hline & Grade & -.048 & -.374 & .709 \\
\hline & Age & -.064 & -.494 & .623 \\
\hline \multirow[t]{6}{*}{ Model 2} & (Constant) & & 2.364 & .020 \\
\hline & Gender & .360 & 4.005 & .000 \\
\hline & Grade & -.027 & -.210 & .834 \\
\hline & Age & -.078 & -.603 & .548 \\
\hline & EPSI Intimacy & .051 & .545 & .587 \\
\hline & IAS Intimacy & -.213 & -2.330 & .022 \\
\hline \multirow[t]{8}{*}{ Model 3} & (Constant) & & 1.661 & .100 \\
\hline & Gender & .303 & 3.282 & .001 \\
\hline & Grade & -.049 & -.389 & .698 \\
\hline & Age & -.089 & -.691 & .491 \\
\hline & EPSI Intimacy & .027 & .289 & .773 \\
\hline & IAS Intimacy & -.158 & -1.674 & .097 \\
\hline & Exploration & .205 & 2.216 & .029 \\
\hline & Commitment & -.015 & -.173 & .863 \\
\hline
\end{tabular}


identity exploration reached statistical significance, $\beta=.205, t(7,108)=2.216, p<.05$. In addition, the beta weight for gender was statistically significant $\beta=.303, t(7,108)=3.282$, $p<.001$. These data did not support the hypothesis that identity variables would account for a greater amount of variance than intimacy variables in YSR internalizing scores, since neither the second or third blocks of predictors accounted for significant proportions of additional variance in YSR internalizing scores.

Table 11 summarizes the results for a second regression equation regressing YSR internalizing symptoms upon levels of identity and intimacy. This second equation reversed the order of entry of the second and third blocks of predictor variables. Variables were entered in three steps: (a) the control variables (age, gender, grade), (b) identity variables (EIPQ exploration and commitment) and, (c) the intimacy variables (IAS intimacy and EPSI intimacy). Variables entered in step one accounted for a significant amount of variance, $\Delta R^{2}=.154$, resulting in a significant equation, $F(3,112)=6.785, p<$ .001 , in which the beta weight for gender reached statistical significance $\beta=.370, t(3,112)$ $=4.068, p<.001$. Identity variables entered in step two accounted for a significant amount of additional variance, $\Delta R^{2}=.055$, and the regression equation remained significant, $F(5,110)=5.814, p<.001$, in which EIPQ identity exploration variable reached statistical significance, $\beta=.242, t(5,110)=2.682, p<.05$. In addition, the beta weight for gender was statistically significant $\beta=.301, t(5,110)=3.246, p<.01$. Intimacy variables entered in step three accounted for a nonsignificant amount of additional variance, $\Delta R^{2}=.021$, yet the regression equation remained significant, $F$ $(7,108)=4.598, p<.001$, in which EIPQ identity exploration reached statistical 
Table 11

Regression Table for Identity and Intimacy Variables Predicting YSR Internalizing Scores

\begin{tabular}{lllllll}
\hline Model 1 & Regression & $\begin{array}{l}\text { Sum of } \\
\text { Squares }\end{array}$ & df & $\begin{array}{l}\text { Mean } \\
\text { Square }\end{array}$ & F & Sig. \\
\cline { 3 - 6 } & Residual & 6331.287 & 112 & 56.529 & & \\
& Total & 7481.966 & 115 & & & \\
Model 2 & Regression & 1563.871 & 5 & 312.774 & 5.814 & .000 \\
& Residual & 5918.094 & 110 & 53.801 & & \\
& Total & 7481.966 & 115 & & & \\
Model 3 & Regression & 1717.801 & 7 & 245.400 & 4.598 & .000 \\
& Residual & 5764.165 & 108 & 53.372 & & \\
\hline
\end{tabular}


Table 11

Regression Table for Identity and Intimacy Variables Predicting YSR Internalizing Scores

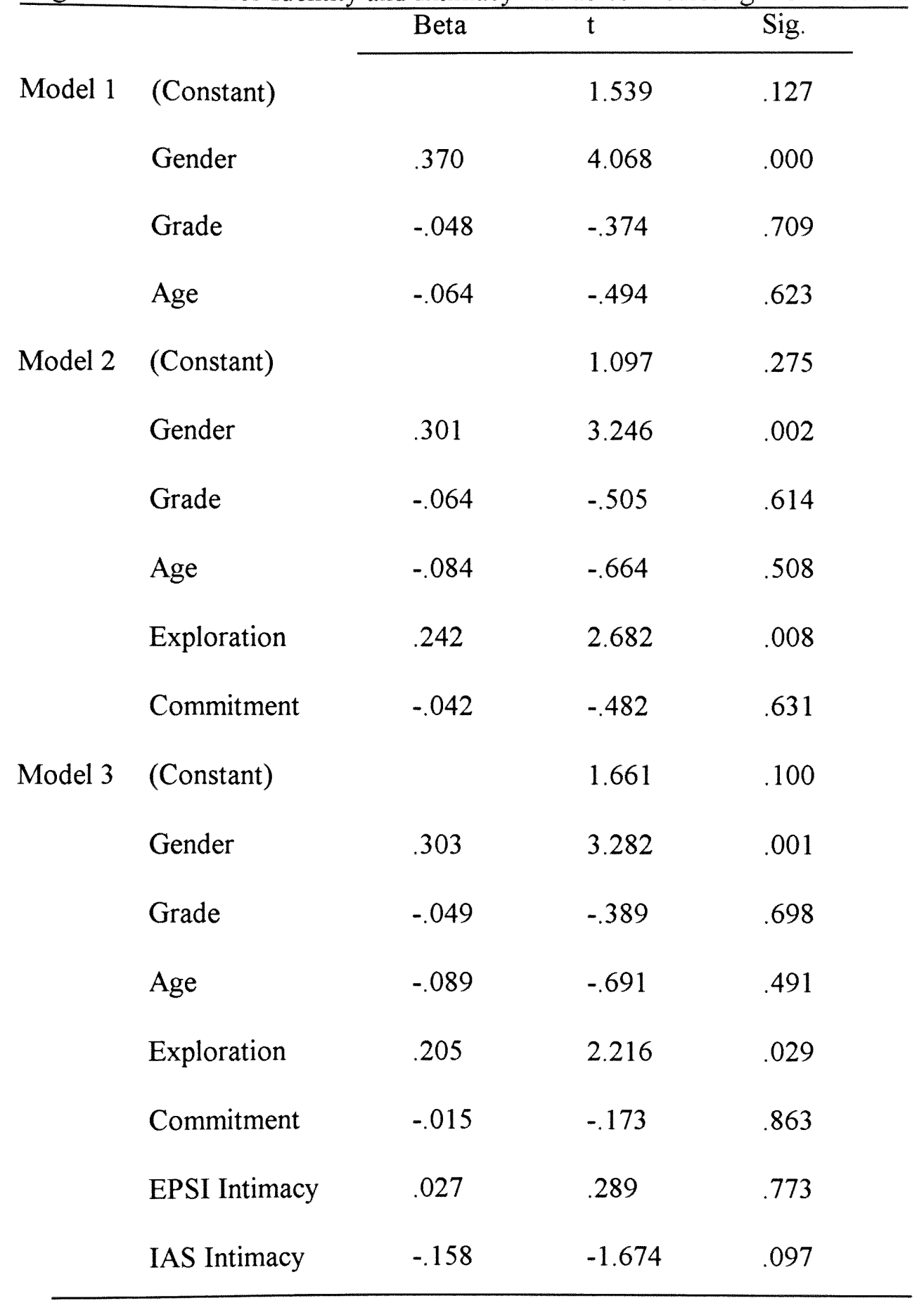


significance, $\beta=.205, t(7,108)=2.216, p<.05$. In addition, the beta weight for gender was statistically significant $\beta=.303, t(7,108)=3.282, p<.001$. Therefore, these data supported the hypothesis that identity variables would account for a greater amount of variance than intimacy variables in YSR internalizing scores, since the second block of predictors accounted for a significant proportion of additional variance in YSR internalizing scores. In contrast, the third block of predictors (i.e., intimacy variables) did not account for a significant proportion of additional variance in YSR internalizing scores. 


\section{CHAPTER 4: DISCUSSION}

Summary of findings

The purpose of this thesis was to empirically investigate whether (a) identity exploration and identity commitment and (b) level of self-reported intimacy could be identified as significant predictors of internalizing and externalizing behavior problems in a predominantly minority sample of alternative school students considered to be at elevated risk for negative developmental outcomes. In addition, gender differences in measures of intimacy and identity were also examined. An understanding of significant relations among these variables in this at-risk population is salient to the development, implementation and evaluation of effective, targeted prevention programs and interventions. Developmental theory and previous empirical research regarding identity development and the development of intimacy have focused on the importance of these issues as general issues, yet many of these studies have utilized unrepresentative samples of adolescents, i.e., samples containing predominantly White, middle-class, and college-aged youth (Hodgson \& Fischer, 1979; Moore \& Boldero, 1991; Prager, 1983; Schiedel \& Marcia, 1985; Tesch \& Whitbourne, 1982, 1985).

In the current study, analyses were performed in order to better understand relations among adolescents' self-reported levels of identity, intimacy, and adjustment. Correlational analyses documented a significant positive association between EIPQ exploration scores and YSR internalizing scores. This finding suggested that greater identity exploration was associated with higher levels of internalizing problems such as 
depression and anxiety. This finding is consistent with previous theory and research showing that identity commitment to be positively related to overall mental health, self esteem, self-concept, well-being (Adams et. al, 1970; Brookins, 1996; Marcia \& Friedman, 1970; Phinney, 1996; Prager, 1982; Schenkel \& Marcia, 1972). The findings of the current study were interesting because identity exploration was the dimension significantly related to internalizing difficulties, whereas commitment was not. This finding could have been a result of the demographic characteristics of the sample, such as their age, minority status, or at-risk classification. The fact that, for this group, the process of identity exploration was related to internalizing difficulties may be related to additional stressors arising from contextual factors not found in previous study samples that were comprised of predominantly White, middle-class college students. Additional studies of alternative school samples are needed to clarify these findings. However, what is clear from both previous research and the results of this study is that identity exploration may produce a lack of coherence, unsuccessfully resolved psychosocial tasks, and a search for meaning associated with internalizing problems, such as feelings of anxiety, low selfesteem, and depression.

The hypothesis that there would be a significant negative relation between intimacy scores and adjustment scores was partially supported by the identification of a significant negative correlation between internalizing symptoms and one of the two intimacy measures. Previous research and theory in the area of adolescent intimacy development and adjustment has suggested a strong relationship between these two constructs (Boldero \& Moore, 1990; Claes, 1992; Erikson, 1968; Gavazzi, Anderson, \& Sabatelli, 1993; 
Rotenberg \& Whitney, 1992; Sullivan, 1953; Wheeler, Reis, \& Nezlek, 1983). It seems that if one is able to establish intimate relationships with family members, friends, and/or romantic partners, then they are less likely to report feelings of isolation and loneliness related to a lack of social interaction and sharing and more likely to experience validation leading to a sense of personal satisfaction and security.

This study utilized two measures of intimacy, the EPSI and the IAS, and a significant relation with adjustment was found for only the IAS, limiting the generalizability of this relation. The lack of results for the EPSI could be a result of a variety of factors, ranging from methodological problems (e.g., the brevity of the measure) to the absence of a strong relationship between intimacy and adjustment in this sample. Use of another measure, such as the Orlofsky Interview, in future research with this population may clarify the relation between intimacy and adjustment. Nevertheless, existing theory and empirical research, including the current findings, support the idea that these adolescents need assistance and encouragement where intimacy issues are concerned because they influence adjustment. Intervention programs targeted to address issues and difficulties that arise in intimate relationships merit further research and development, and if shown to be efficacious, broad implementation.

With regard to gender differences, univariate tests for individual identity, intimacy, and adjustment variables revealed significant gender differences for identity exploration, with females reporting significantly higher scores than males, as well as for internalizing symptoms, with females reporting significantly higher scores than males. The results of 
this study did not support Kroger's (1997) conclusion, after reviewing the available literature, that males and females have a similar style when approaching identity-defining issues. The demographic characteristics of this sample may have played a significant role in these findings and additional research using samples of at-risk youth is needed. There is some research indicating that adolescent girls may have a ruminative coping style that may result in higher scores on measures of depression (Nolen-Hoesksema \& Girgus, 1999). However, these results seem to indicate that for this sample, males and females did not approach identity exploration in a similar way, nor did they report or experience their internalizing difficulties to the same degree.

Finally, regression analyses demonstrated that even after gender was statistically controlled, identity exploration scores accounted for a larger proportion of additional variance in internalizing scores than did intimacy scores. For adolescents who reported higher levels of identity exploration, and therefore greater internalizing symptoms, adolescence is a period of time during which processes of identity exploration may result in transient increases in confusion, nervousness, and uncertainty that leads to depression, withdrawal, and other internalizing difficulties. These findings highlight the need for additional research into relations between identity development and general indices of adjustment with diverse samples of adolescents. These findings may also lend support to the need for the development and evaluation of targeted interventions that are aimed at addressing identity development issues, as well as related difficulties with internalizing problems that may be encountered during adolescence, while maintaining sensitivity to gender differences. This study highlights the reason that this sample was targeted for 
interventions related to identity development and the development of intimacy, through workshops on Making Life Choices, Anger Management, Relationships, and Alternative Lifestyles (Ferrer-Wreder, 1998; Ferrer-Wreder, et. al., 1998; Lorente, 1998).

Externalizing difficulties did not appear to be predicted by identity or intimacy development for this sample, contrary to the stated hypothesis. There are several potential reasons why no significant relations were documented. There may be little variance in externalizing difficulties in this sample, for two entirely different reasons. The first, and the most optimistic explanation, suggests that externalizing behaviors are situation specific and therefore less stable over time. Specifically, this sample is recruited from a very strict drop-out prevention program that closely monitors the on- and off-campus behaviors of its students, potentially reducing the externalizing difficulties of those students. A second plausible explanation suggests that this sample, by its very nature, has elevated levels of externalizing difficulties, with little variance between participants that can be accounted for by the predictor variables in this study. The data collected for this study did not allow comparisons between different types of samples; therefore these explanations must remain speculative.

With regard to the development of interventions, one implication may be that students attending alternative educational programs are more likely to display internalizing behavioral difficulties. Effective intervention programs may require educators and practitioners to emphasize internalizing difficulties, focusing on identity and intimacy issues particular to each gender. Interventions that are able to decrease the severity of the 
problems encountered during exploration in identity development by assisting adolescents in making important choices, e.g., via skills development to increase self-directed decisionmaking, may alleviate some of the internalizing difficulties experienced during this period. In addition, programs that address the development and maintenance of relationships (including those with family, friends, and dating partners) may also help decrease internalizing difficulties.

\section{Limitations and directions for future research}

Limitations of this study include sample and data issues, since the sample is a selected sample with all participants being from the same school. A broader recruitment and sampling strategy would include samples from more schools, different types of schools, and a larger sample size. Finally, the sample used for this study ranged from age 14 to age 19 , which may mix participants representing different adolescent developmental stages (e.g., early, middle, late). These sampling issues limit the generalizability of the results to adolescent populations that have similar issues, including adolescents with the same at-risk and minority status or those who participate in an alternative education program. Additional limitations in this study that limit generalizability are related to the data used and include the use of cross-sectional, correlational data which limit the construction of causal statements. Therefore, the findings of the current study must necessarily focus on associations, rather than patterns of cause and effect. Another data issue is the use of self-report formats and unpublished measures that need additional 
validation and empirical support. Several of the measures had low levels of internal consistency, which may have potentially limited the reliability of the results.

Future research should continue to gain a better understanding of relations among identity, intimacy, and gender and how they affect adolescent development and adjustment in vulnerable minority samples. Whether it be for parents, teachers, clinicians, or researchers, information that helps to create effective interventions where the need is greatest for every type of adolescent population is essential. Minority adolescents and those considered at-risk have rarely been the focus of research on the development of identity and intimacy. Therefore, the need for accurate information is great. Effective, targeted interventions are the product of targeted research that strives to clarify, broaden, and enhance the existing research literature, by including the use of samples other than middle-class, White, college students. In conclusion, this study contributes valuable research to the available literature on the development of identity and intimacy and their relation to adolescent adjustment among at-risk, predominantly minority, adolescents. This is a sample that deserves attention and needs effective interventions. The results of this study highlight the need to continue to target identity-defining issues during adolescence, including making good choices, increasing personal control, and enhancing personal relationships, including those with family members, friends, and dating partners. Such an intervention may prevent normal stresses related to the development of identity or intimacy from becoming significant negative influences on adolescent mental health. 


\section{List of References}

Academy for community education: Student handbook. (1996-1997). (Available from the Academy for Community Education, Zamora Road, Coral Gables, FL, 33145).

Achenbach, T. M. (1991). Manual for the Youth Self-Report and 1991 Profile. Burlington, VT: University of Vermont, Department of Psychiatry.

Adams, G. R., \& Archer, S. L. (1994). Identity: A precursor to intimacy. In S. L. Archer (ed.), Interventions for adolescent identity development. Thousand Oaks, CA: Sage.

Adams, G. R., Openshaw, D. K., Bennion, L., Mills, T., \& Noble, S. (1988) Loneliness in late adolescence: A social skills training study. Journal of Adolescent Research, 3, 81-96.

Archer, S. L. (1982). Intimacy Interview. Personal correspondence. September, 1996.

Archer, S. L. (Ed.). (1994). Interventions for adolescent identity development. Thousand Oaks, CA: Sage.

Archer, S. L. \& Waterman, A. S. (1988). Psychological individualism: Gender differences or gender neutrality? Human Development, 31, 65-81.

Arrufat, O. (1995). The Refinement and Validation of a Measure of Critical Thinking and Problem Solving. Unpublished master's thesis, Florida International University, Miami.

Balistreri, E., Busch-Rossnagel, N. A., \& Geisinger, K. F. (1995). Development and preliminary validation of the Ego Identity Process Questionnaire. Journal of Adolescence, 18, 179-190.

Bartle-Haring, S. \& Strimple, R. E. (1996). Association of identity and intimacy: An exploration of gender and sex-role orientation. Psychological Reports, 79, 12551264.

Berman, A. (1996). Making Relationships Work Workshop. Unpublished master's thesis, Florida International University, Miami.

Berman, A., Lorente, C. C., Martinez, M.\& Kurtines, W. (1997, March). The Intimacy Assessment Scale: The development and validation of a psychosocial measure. Poster presented at the annual meeting of Society for Research on Identity Formation. Miami Beach, FL. 
Berman, S., Berman, A., Lorente, C. C., Ferrer, L. A., Arrufat, O., Kurtines, W. M. (1996, March). Making life choices workshop. Poster session presented at the annual meeting of Society for Research on Adolescents, Boston, MA.

Berndt, T.J. (1992). Friendship and Friends: influence in adolescence. Current Directions in Psychological Science, 1, 156-159.

Berndt, T. J., \& Perry, T. B. (1990). Distinctive feature and effects of early adolescent friendships. In R. Montemayor, G. Adams \& T. Gullota (Eds.), Advances in adolescent research, Vol. 2. Beverly Hills, CA: Sage.

Brookins, C. C. (1996). Exploring psychosocial task resolution and self-concept among African-American adolescents. Perceptual and Motor Skills, 82, 803-810.

Buhrmester, D. \& Furman, W. (1986). The changing functions of friends in childhood: A Neo-Sullivanian perspective. In V. J. Derlega \& B. A. Winstead (Eds.), Friendship and social interaction_(pp.41-62). New York: Springer-Verlag.

Buhrmester, D. \& Furman, W. (1987). The development of companionship and intimacy. Child Development, 58, 1101-1113.

Camp, B. W. \& Bash, M. S. (1985). Think aloud: Increasing social and cognitive skill - a problem-solving program for children. Champaign, IL: Research Press.

Claes, M. E. (1992). Friendship and personal adjustment during adolescence. Journal of Adolescence, 15, 39-55.

Constantinople, A. (1970). Some correlates of average level of happiness among college students. Developmental Psychology, 2(3), 447.

Douvan, E. \& Adelson, J. (1966). The adolescent experience. New York: Wiley.

Dunn, J. (1993). Young children's close relationships. Newbury Park, CA: Sage.

Dyk, R. H. \& Adams, G. R. (1990) Identity and intimacy: An initial investigation of three theoretical models using cross-lag panel correlations. Journal of Youth and Adolescence, 19(2), 91-110.

Eaton, Y. M., Mitchell. M. L., \& Jolley, J. M. (1991). Gender differences in the developmental of relationships during late adolescence. Adolescence, 26, 565-568.

Enright, R. D., Ganiere, D. M., Buss, R. R., Lapsley,D. K., \& Olson, L. M. (1983). Promoting identity development in adolescents. Journal of Early Adolescence, 3, 247-255. 
Enright, R. D., Olson, L. M., Ganiere, D., Lapsley, D. K., \& Buss, R. R. (1984). A clinical model for enhancing adolescent ego identity. Journal of Adolescence, 7, 119-130.

Erikson, E. H. (1963). Childhood and Society. New York: Norton.

Erikson, E. H. (1968). Identity: Youth and crisis. New York: Norton.

Erikson, E. H. (1980). Identity and the life cycle. New York: Norton.

Erikson, E. H. (1980). Growth and crises of the healthy personality. In E. H. Erikson, Identity and the life cycle (pp.51-107). New York: Norton.

Ferrer (1996). Women's identity in postmodern and feminine landscapes. Unpublished manuscript, Florida International University, Miami.

Ferrer-Wreder, L. (1998). Making Life Choices Workshop. Unpublished dissertation, Florida International University, Miami.

Ferrer-Wreder, L., Lorente, C. C., Kurtines, W., Briones, E., Bussell, J., Berman, S., \& Arrufat, O. (1998). Identity development for marginalized youth. Journal of Adolescent Research, 17 (2), 168-187.

Fromm, E. (1947). Man for himself: An inquiry into the psychology of ethics. New York: Holt, Rinehart \& Winston.

Gavazzi, S M., Anderson, S. A., \& Sabatelli, R. M. (1993). Family differentiation, peer differentiation, and adolescent adjustment in a clinical sample. Journal of Adolescent Research, 8, 205-225.

Gulotta, T., Adams, G., \& Montemayor, R. (1990). Developing social competencies in adolescence. Newbury Park, CA: Sage.

Hodgson, J. W., \& Fischer, J. L. (1979). Sex differences in identity and intimacy development in college youth. Journal of Youth and Adolescence, 8, 37-50.

Howard, S. M. \& Kubis, J. F. (1964). Ego identity and some aspects of personal adjustment. Journal of Psychology, 58(2), 459-466.

Kazdin, A. E. (1988). Child Psychotherapy: Developing and identifying effective treatments. New York: Pergammon.

Krueger, R. F., Schmutte, P. S., Caspi, A., \& Moffitt, T. E. (1994). Personality traits are linked to crime among men and women: Evidence from a birth cohort, Journal of Abnormal Psychology, 103(2), 328-338. 
Kroger, J. (1997). Gender and identity: The intersection of structure, content, and context. Sex Roles, 36, 747-770.

Kurtines, W. M. \& Gewirtz, J. L. (1984). Morality, moral behavior, and moral development. New York: John Wiley \& Sons.

Kurtines, W. M., \& Gewirtz, J. L. (1987). Moral development through social interaction. New York: John Wiley \& Sons.

Kurtines, W. M., \& Gewirtz, J. L. (1991). The Handbook of Moral behavior and development; Theory, Research and application (Vols. 1-3). Hillsdale, NJ: Lawrence Erlbaum Associates.

Kurtines, W. M., Berman, S. L., Ittel, A., \& Williamson, S. (1995). Moral development: A co-constructivist perspective. In W. M. Kurtines \& J. L. Gewirtz (Eds.), Moral development: An introduction. New York: Wiley.

Kurtines, W. M. (1998). Human behavior and development: A co-constructivist perspective. Unpublished manuscript, Florida International University, Miami.

Lewin, K. (1935). A dynamic theory of personality. New York: McGraw-Hill.

Lorente, C. C. (1997). Gender differences in ego identity. Unpublished manuscript, Florida International University, Miami.

Lorente, C. C. (1998). Building better relationships workshop: An intervention fostering identity formation and interpersonal development in middle adolescents.

Unpublished doctoral dissertation, Florida International University, Miami.

Lorente, C. C. (2002). Personal communication, March 28, 2002.

Marcia, J. (1966). Development and validation of ego identity status. Journal of Personality and Social Psychology, 5, 551-558.

Marcia, J. (1967). Ego identity status: Relationship to change in self-esteem, "general maladjustment", and authoritarianism. Journal of Personality, 35(1), 119-133.

Marcia, J. (1991). Identity and self-development. In R. Lerner, A. Petersen \& J. BrooksGunn (Eds.), Encyclopedia of adolescence (pp.529-534) New York: Garland.

Marcia, J. E. (1993). The ego identity status approach to ego identity. In J. E. Marcia, A. S. Waterman, D. R. Matteson, S. L. Archer, \& J. L. Orlofsky (Eds.) Ego identity: $A$ handbook for psychosocial research. New York: Springer-Verlag. 
Marcia, J. E. \& Friedman, M. L. (1970). Ego identity status in college women. Journal of Personality, 38(2), 249-263.

Marcia, J. E., Waterman, A. S., Matteson, D. R., Archer, S. L., \& Orlofsky, J. L. (1993). Ego identity: A handbook for psychosocial research. New York: SpringerVerlag.

Markstrom-Adams, C. \& Adams, G. R. (1995). Gender, ethnic group, and grade differences in psychosocial functioning during middle adolescence. Journal of Youth and Adolescence, 6, 353-379.

McAdams, D. P. \& Vaillant, G. E. (1982). Intimacy motivation and psychosocial adjustment: A longitudinal study. Journal of Personality Assessment, 46, 586-593.

Milnitsky, C., Ferrer-Wreder, L., Lorente, C. C., Briones, E., \& Kurtines, W. (1997). Transformative education in cultural context: Education for democracy in Brazil and the United States. Unpublished manuscript, Universidade Federal do Rio Grande do Sul \& Florida International University.

Moffit, T. E., Caspi, A., Dickson, N., Silva, P., \& Stanton, W. (1996). Childhood-onset versus adolescent-onset antisocial conduct problems in males: Natural history from ages 3 to 18 years. Development \& Psychopathology, 8(2), 399-424.

Moore, S. \& Boldero, J. (1991). Psychosocial development and friendship functions in adolescence. Sex Roles, 25(9/10), 521-536.

Newcombe, A. F., \& Bagwell, C. L. (1995). Children's friendship relations: A metaanalytic review. Psychological Bulletin, 117, 306-347.

Nielsen, L. (1996). Adolescence: A contemporary view. New York: Harcourt Brace.

Nolen-Hoeksema, S. \& Girgus, J. S. (1999). Ruminations: Gender plays role in adolescent depression. Advance for Speech-Language Pathologists \& Audiologists, February 22, 5.

Orlofsky, J. (1973). Ego identity status and the intimacy versus isolation crisis of young adulthood. Journal of Personality and Social Psychology, 27, 211-219.

Orlofsky, J., Marcia, J., and Lesser, I. (1973). Ego identity status and the intimacy versus isolation crisis of young adulthood. Journal of Personality and Social Psychology, 27, 211-219.

Paul, E. L., \& White, K. M. (1990). The development of intimate relationships in late adolescence. Adolescence, 25, 375-400. 
Phinney, J. (1990). Ethnic identity in adolescents and adults: A review of research. Psychological Bulletin, 108, 499-514.

Phinney, J. (1993). A three-stage model of ethnic identity development. In M. Bernal \& G. Knight (Eds.), Ethnic identity: Formation and transmission among Hispanics and other minorities, (pp. 61-79). Albany: State University of New York Press.

Phinney, J. (1996). When we talk about American ethnic groups, what do we mean? American Psychologist, 51, 918-927.

Piaget, J. (1932/1965). The moral judgment of the child. (M. Gabain, Trans.), New York: Free Press. (Originally published 1932).

Pinsker, H., Nepps, P., Redfield, J., \& Winston, A. (1985). Applicants for short-term dynamic psychotherapy. In A. Winston (Ed.), Clinical and research issues in short-term dynamic psychotherapy (pp. 104-116). Washington, DC: American Psychiatric Association.

Prager, K. J. (1982). Identity development and self-esteem in young women. Journal of Genetic Psychology, 14(2), 177-182.

Prager, K. J. (1983). Development of intimacy in young adults, a multi-dimensional view. Psychological Reports, 52, 751-756.

Raskin, P. M. (1985). The relationship between identity and intimacy in early adulthood. The Journal of Genetic Psychology, 147(2), 167-181.

Raskin, P. M., \& Waterman, A. S. (1994). On the bidirectional impact of counseling on identity and intimacy development. In S. L. Archer (ed.), Intervention for adolescent development (pp. 214-220). Thousand Oaks, CA: Sage.

Reis, H. T. (1990). The role of intimacy in interpersonal relations. Journal of Social and Clinical Psychology, 9(1), 15-30.

Reis, H. T. \& Shaver, P. (1988). Intimacy as an interpersonal process. In S. Duck (Ed.), Handbook of personal relationships (pp. 367-389). Chichester: Wiley.

Reis, H. T., Wheeler, L., Kernis, M. H., Speigel, N., \& Nezlek, J. (1985). On specificity in the impact of social participation on physical and psychological health. Journal of Personality and Clinical Psychology, 48, 456-471.

Rosenthal, D. A., Gurney, R.M., \& Moore, S. M. (1981). From trust to intimacy: A new inventory for examining Erikson's stages of psychosocial development. Journal of Youth and Adolescence, $10,525-537$. 
Rotenberg, K. J. \& Whitney, P. (1992). Loneliness and disclosure processes in preadolescence. Merrill-Palmer Quarterly, 38, 401-416.

Rutter, M. (1990). Psychosocial resilience and protective mechanisms. In J. Rolf, A. S. Masten, D. Cicchetti, K. H., Neuchterlein, \& E. Weintraub (Eds.), Risk and protective factors in the development of psychopathology (pp. 316-331). New York: Cambridge University Press.

Sanderson, C. A. \& Cantor, N. (1995). Social dating goals in late adolescence: Implications for safer sexual activity. Journal of Personality and Social Psychology, 68, 1121-1134.

Schenkel, S., \& Marcia, J. E. (1972). Attitudes toward pre-marital intercourse in determining ego identity status in college women. Journal of Personality, 3, 472482 .

Schiedel, D. G. \& Marcia, J. E. (1985). Ego identity, intimacy, sex role orientation, and gender. Developmental Psychology, 21, 149-160.

Skiades, P. (1996). Relationship Quality Scale. Unpublished master's thesis, Florida International University, Miami.

Spivack, G., Platt, J. J., \& Shure, M. B. (1976). The problem-solving approach to adjustment. San Francisco: Jossey-Bass.

Spivack, G., \& Shure, M. B. (1982). The cognition of social adjustment: Interpersonal cognitive problem-solving and thinking. In B. B. Lahey, \& A. E. Kazdin (Eds.), Advances in clinical psychology (vol. 5). (pp. 323-372). New York: Plenum.

Steinberg, L. (1996). Adolescence. New York: McGraw-Hill.

Sullivan, H.S. (1953). The interpersonal theory of psychiatry. New York: Norton.

Tesch, S. A. \& Whitbourne, S. K. (1982). Intimacy and identity status in young adults. Journal of Personality and Social Psychology, 43, 1041-1051.

Townsend, M. A., McCracken, H. E., \& Wilton, K. M. (1998). Popularity and intimacy as determinants of psychological well-being in adolescent friendships. Journal of Early Adolescence, 8, 421-436.

Veroff, J., Douvan, E., \& Kulka, R. A. (1981). Mental Health in America: Pattern of help-seeking from 1957-1976. New York: Basic Books. 
Waterman, A. (1992). Identity development from adolescence to adulthood: An extension of theory and a review of research, Developmental Psychology, 18, 341-358.

Wheeler, L., Reis, H. T., \& Nezlek, J. (1983). Loneliness, social interaction, and sex roles. Journal of Personality and Social Psychology, 45, 943-953.

Whitborne, S. K., \& Tesch, S. A. (1985). A comparison of identity and intimacy statuses in college students and alumni. Developmental Psychology, 21, 1039-1044.

Winstanley, M. R., Meyers, S. A., \& Florsheim, P. (2000). Psychosocial correlates of intimacy achievement among adolescent fathers-to-be. Journal of Youth and Adolescence, 31, 91-100.

Wolf, L. (1996). Making Relationships Work Workshops. An intervention for high school students. Unpublished manuscript, Florida International University, Miami.

Yufit, R. (1956). Intimacy and isolation: Some behavioral and psychodynamical correlates. Unpublished doctoral dissertation, University of Chicago.

Youniss, J. \& Smollar, J. (1985). Adolescent relations with mothers, fathers, and friends. Chicago: University of Chicago Press. 
Appendix A

Measures 
EGO IDENTITY PROCESS QUESTIONNAIRE

Please bubble in the appropriate number on the enclosed answer sheet.

$\begin{array}{ccllc}1 & 2 & 3 & 4 & 5 \\ \text { Definitely } & \text { Somewhat } & \text { Not } & \text { Somewhat } & \text { Definitely } \\ \text { Not True } & \text { Not True } & \text { Sure } & \text { True } & \text { True }\end{array}$

1 I have definitely decided on the career I want to pursue.

2 I don't expect to change my political principles and ideals.

3 I have considered accepting different kinds of religious beliefs.

$4 \quad$ There has never been a need to question my values.

5 I am very confident about what kinds of friends are best for me.

6 My ideas about what it is to be a man or woman have never changed as I became older.

7 I will always vote for the same political party.

8 I have firmly held views concerning my role in my family.

9 I have engaged in several discussions concerning behaviors involved in dating relationships.

10 I have considered different political views thoughtfully.

11 I have never questioned my views concerning what kind of friend is best.

12 My values are likely to change in the future.

13 When I talk to people about religion, I make sure to add my opinion.

14 I am not sure about what type of dating relationship is best for me.

15 I have not felt the need to reflect on the importance I place on my family.

16 Regarding religion, my views are likely to change in the near future.

17 I have definite views regarding the ways in which men and women should behave.

18 I have tried to learn about different careers to find the best one for me.

19 I have undergone several experiences that made me change my views on what it is to be a man or woman. 
20 I have re-examined many different values in order to find the ones which are best.

21 I think what I look for in a friend could change in the future.

22 I have questioned what kind of date is right for me.

23 I am unlikely to alter my career goals.

24 I have evaluated many ways in which I fit into my family.

25 My ideas about what it is to be a man or woman will never change.

26 I have never questioned my political beliefs.

27 I have had many experiences that led me to review the qualities that I would like my friends to have.

28 I have discussed religious matters with a number of people who believe differently than I do.

29 I am not sure that the values I hold are right for me.

30 I have never questioned my career goals.

31 The extent to which I value my family is likely to change in the future.

32 My beliefs about dating won't change. 


\section{Intimacy Assessment Scale}

In this study, we are interested in knowing about how you feel and think about your close relationships. Think about how you feel in general about your past and present close relationships. Each question asks about how strongly you agree with each statement for three different relationship categories - friendship, family and dating.

$\begin{array}{llccr}\text { Always } & \text { Mostly } & \text { Neutral } & \text { Mostly } & \text { Always } \\ \text { false } & \text { false } & & \text { true } & \text { true } \\ 1 & 2 & 3 & 4 & 5\end{array}$

A) At times, I prefer being alone over being with my:

1) friends

2) family

3) dating partner

B) I feel very comfortable when my -----------express their affection towards me.

4) friends

5) family

6) dating partner

C) Sometimes I feel that I do not provide enough care and emotional support for my:

7) friends

8) family

9) dating partner

D) I seem to be over-involved with my:

10) friends

11) family

12) dating partner 


$\begin{array}{llccc}\text { Always } & \text { Mostly } & \text { Neutral } & \text { Mostly } & \text { Always } \\ \text { false } & \text { false } & & \text { true } & \text { true } \\ 1 & 2 & 3 & 4 & 5\end{array}$

E) I have concerns about being emotionally dependent on my:
13) friends
14) family
15) dating partner

F) I totally feel that commitment and .............go hand in hand.

16) friendship

17) family

18) dating

G) I always like it when my rely on me.

19) friends

20) family

21) dating partner

H) I am not always sure that my secrets are safe with my:

22) friends

23) family

24) dating partner

I) There are some extremely personal aspects of my life that I will not discuss with my:

25) friends

26) family

27) dating partner 


$\begin{array}{llccc}\text { Always } & \text { Mostly } & \text { Neutral } & \text { Mostly } & \text { Always } \\ \text { false } & \text { false } & & \text { true } & \text { true } \\ 1 & 2 & 3 & 4 & 5\end{array}$

J) I sometimes show restraint when it comes to being affectionate with my:

28) friends

29) family

30) dating partner

K) My ............... should always tell me things that are considered to be personal.

31) friends

32) family

33) dating partner

L) Sometimes when my ........... hold viewpoints which differ from my own I am not able to respect their view.

34) friends

35) family

36) dating partner

M) When my .......... offer me a lot of care and emotional support, it sometimes makes me feel uncomfortable.

37) friends

38) family

39) dating partner 


$\begin{array}{llccc}\text { Always } & \text { Mostly } & \text { Neutral } & \text { Mostly } & \text { Always } \\ \text { false } & \text { false } & & \text { true } & \text { true } \\ 1 & 2 & 3 & 4 & 5\end{array}$

N) I always show my respect, even when I feel like they aren't respecting me.

40) friends

41) family

42) dating partner

O) I am never completely comfortable relying on my:

43) friends

44) family

45) dating partner

P) I have trouble keeping:

46) close friends

47) close family relationships

48) close dating relationships

Q) Sometimes my ............."think twice" about confiding in me.

49) friends

50) family

51) dating partner

R) Sometimes there are things that I wish my would not tell me.

52) friends

53) family

54) dating partner 


$\begin{array}{llccc}\text { Always } & \text { Mostly } & \text { Neutral } & \text { Mostly } & \text { Always } \\ \text { false } & \text { false } & & \text { true } & \text { true } \\ 1 & 2 & 3 & 4 & 5\end{array}$

S) At times, I think my are overly involved in my life.

55) friends

56) family

57) dating partner

T) I believe that my and I should not become too deeply involved.

58) friends

59) family

60) dating partner

U) I think that it is absolutely crucial for my to always show consideration towards me.

61) friends

62) family

63) dating partner

V) I sometimes have reservations about revealing personal information about myself to:

64) friends

65) family

66) dating partner 


$\begin{array}{llccc}\text { Always } & \text { Mostly } & \text { Neutral } & \text { Mostly } & \text { Always } \\ \text { false } & \text { false } & & \text { true } & \text { true } \\ 1 & 2 & 3 & 4 & 5\end{array}$

X) At times, I prefer being with my ........... over being alone.

70) friends

71) family

72) dating partner

W) I feel that I need to have extremely close relationships with my:

67) friends

68) family

69) dating partner

Y) I am always praised by my for my active participation and involvement.

73) friends

74) family

75) dating partner

Z) I believe that it is absolutely necessary for my to always respect my beliefs.

76) friends

77) family

78) dating partner 